\title{
Norwegen, das Papsttum und Europa im 13. Jahrhundert
}

\author{
Mechanismen der Integration
}

Von

\section{Martin Kaufhold}

Jürgen Miethke zum sechzigsten Geburtstag

Eines der großen und reizvollen Themen der europäischen Entwicklung, der gegenwärtigen wie der geschichtlichen, ist das Verhältnis der europäischen Kernländer 7u den Randzonen. Systematisch gesprochen ist es das Problem von Zentrum und Peripherie. Es ist auch ein Problem des Grades der Integration, der daraus entstehenden Verpflichtungen und der Möglichkeit zur Distanzierung. Für Konfliktstoff sorgt in besonderer Weise das Verhältnis von kultureller Identität zu übergreifenden Normen, die in der Randlage mit ihren besonderen Lebensbedingungen häufig als Disziplinierung verstanden werden. Eine Wahrnehmung, deren kritischer Kern durchaus zu einer Absage an den gesamten Integrationsprozeß führen kann, wie die Ablehnung der EU-Mitgliedschaft durch die Norweger zuletzt deutlich gezeigt hat. Dieser konfliktreiche Prozeß $B$ ist aber keineswegs eine eigentümliche Erscheinung der neueren Geschichte. Sowohl der Vorgang der bewußten Integration in eine historische, kulturelle und politische Entwicklung als auch seine Mechanismen sind an manchem mittelalterlichen Beispicl deutlich erkennbar. Ein sehr anschauliches Beispiel bietet Norwegen im 13. Jahrhundert unter seinem König Hăkon Håkonarsson (1217-1263), der eine entschieden positive Auffassung von der europäischen Integration seines Landes vertrat. Dic Überlieferung erlaubt anhand einer Fallstudie des Verhältnisses dieser nördlichsten Region der christlichen Welt zum Zentrum Europas einen Blick auf die Bezichung von kultureller Identität und europäischer Orientierung unter Einbezichung einer wesentlichen vermittelnden Instanz: der universalen Kirche. Finer Kirche, deren Erscheinung für die Norweger zentrale europäische Werte repräsentierte, deren Universalität aber auch ein Problem darstellte, denn die 
unterschiedlichen Bedingungen der Seelsorge in Rom und am Polarkreis waren evident. Daraus ergaben sich auch Konflikte, aber noch bevor sich dabei die Frage der Disziplinierung stellte, stellte sich die Frage der Information, des Kenntnisstandes vom jeweils anderen: Unde cum insula ipsa sit in tam extremis mundi partibus constituti, quod inde nulli aut rarissimi ad apostolicam sedem accedunt ... so charakterisierte Innozenz IV. (1243-1254) nicht lange nach seinem Amtsantritt die Kommunikationssituation und dementsprechend seinen Kenntnisstand hinsichtlich der Ereignisse in Island. ') Der Brief des Papstes war an den Erzbischof von Trondheim gerichtet. Dessen Erzbistum, nach damaliger Bezeichung hieß es Nidaros, umfaßte die hier untersuchten Schauplätze. Seit der Errichtung seiner Erzdiözese durch den Kardinallegaten Nikolaus von Albano 1154 stand der Metropolit des Nordens der Seelsorge in fünf norwegischen Bistümern, auf den Färöern, den Hebriden und Orkney-Inseln und auch auf Island und Grönland vor. ${ }^{2}$ ) Dies war die nördliche Peripherie der damaligen Christenheit, deren Verhältnis zu Europa wir im folgenden untersuchen wollen. ${ }^{3}$ ) Dabei wirkt dic Randlage noch in neuester Zeit nach, denn das Forschungsinteresse an der norwegischen Entwicklung ist in der deutschen Geschichtsschreibung durchaus überschaubar. Eine intensivere Be-

1) Diplomatarium Norvegicum (künftig: DN). Bd. 1-21. Christiania 1847-1976. hier Bd. 7/1, Nr. 15.

2) Norges Gamle Love (künfig: NGL). Bd. 1. Christiania 1846, 439-441: vgl. dazu Philipp Zorn, Stalat und Kirche in Norwegen bis zum Schlusse des Dreizchnten Jahrhunderts. München 1875. 87-90. Vgl, zu Grönland und lsland: Hermann Notharp, Das Grönlandbistum Gardar, in: ZRG KA 50, 1964, 1-.77: zur Legation des Kardinals Nikolaus, der später als Hadrian IV. Papst wurde. vgl. Robert Brever, Die Legation des Kardinalbischots Nikolaus von Albano in Skandinavien. (Programm der städtischen Realschule zu Halle/S. 1893.) Halle 1893; Johames Barhmann. Die päpstlichen Legaten in Deutschland und Skandinavien 1125-1159. Berlin 1913, 113-121: Edith Martha Almedingen, The English Pope (Adrian IV). I condon 1925. 78-12.3: Wolfgang Secegrïn. Das Papstlum und Skandinavien bis zar Vollendlung der nordischen Kirchenorganisation (1164). (Quellen u. Forsch. \%. Gesch. Schleswig-Holsteins, 51.) Neumünster 1967. 146-166.

3) /u den geographischen Vorstellungen vgl. die Beitrigge in Dagmar linverhan Kurt Schietsel (Hrsg.). Das Danewerk in der Kartographicgeschichte Nordeuropas. Neuminster 1993. Zu dem wichtigen kulturgeschichtlichen Problem von Zentrum und Peripherie sind mir für dass Mittelalter keine Publikationen bekannt. die sich mil den dezidierten Studien von Eduard W. Said, Orientalism. New York 1979, und ders., Culture and Imperialism. New York 1993. vergleichen ließen. Die Studie von Jamel L. Abte-lughod. Before Luropean Hegemony: The World-System $A$. D. 1250-1350. New York/Oxford 1989, trägt zu unserem Problem nichts bei. 
schäftigung mit dem Problem liegt schon längere Zeit zurück, insofern steht nicht nur die Fragestellung, sondern auch der Kenntnisstand in einer Tradition, die bis in dic Jahre Innozenz' IV. und darüber hinaus zurückgeht. ${ }^{4}$ ) Der päpstliche Stuhl bietet auch den Ausgangspunkt für unsere Untersuchung, präziser: das Verhältnis der Norweger, Isländer und Grönländer zur römischen Kurie. ${ }^{5}$ ) Dabei soll uns dic Intensivierung dieses Verhältnisses als ein bedeutender Aspekt der norwegischen Inte-

†) Aus der älteren Forschungsliteratur zu Norwegen seien hier stellvertretend genannt: Konrad Maurer. Dic Bekehrung des norwegischen Stammes zum Christentume. 2 Bde. München 1855/56: Zorm, Stat und Kirche (wic Anm. 2); Walther Holtzmann, Krone und Kirche in Norwegen im 12. Jahrhundert (Englische Annalcklen (II), in: DA 2, 1938. 341-400). Ein Sonderaspekl des Problems, nänlich dic Beziehungen zwischen Norwegen und der Hanse. hat im Bereich der Hansegeschichtsforschung zu einer teils polemischen, teils fruchtbaren Diskussion geführt. und hier sind in jüngster atch wertvolle neue Anregungen gegeben worden: Volker Hem/Arnved Nedkithe (Hrsg.). Norwegen und die Hanse. Wirtschaftliche und kulturelle Aspekte im europäischen Vergleich. (Kicler Werkstücke, Rh. A, 11.) Frankfurt am Main 1994. lü̈r eine Zusammenfassung der älteren Diskussion vgl. Jolm Allyne Gade. The Ilanseatic Control of Norwegian Commerce during the Late Middle Ages. Leiden 1951; Maria Wetki. Studien zum Hanse-Norwegen Problem. in: Hans(ibll 70. 1951, 34-83: Johem Schreine'; Bemerkungen zum Hanse-Norwegen Problem. in: ebd. 72, 1954, 64-78: Knat Helle. Neneste norwegische liorschungen uber deutsche Kaufleute in Norwegen, in: ebd. 98. 1980. 23-38.

5) $7 u$ dem Themal rönische Kurie und Norwegen gibt es ebenfalls eine übersichtliche Literatur. wohei neuere Titel die Untersuchung nicht bis zu unserem 7eitraum führen. sondern sich auf dic früheren Jahrhunderte beschränken: Hector Frederik Jansen Exarup, Idea Hierarchiae Romanate qualis seculo XIII in Scandinavia pracsertim exstiterit. Kopenhagen 1817: Maure): Bekchrung (wic Amm. 4): \%om. Staal und Kirche (wie Anm. 2): (Gustow Adolf Donne' Kardinal Wilhelm von Sabina. Bischof von Modena 1222-1234. Piapselicher legal in den Nordischen Liandern. (Soc. Scient. Fennica Comm. Hum. L.itl., II, 5.) Helsinki 1929; Lutrien Musse't. Lat Pénétration chretienne dans l'Europe du Nord et son Influence sur la civilisation Scandinase. in: Settimane di studio de Centro Italiano di studi sull $A$ lto Mediocvo 14. 1967. 26.3-326: Soegrim. Papstum (wie Anm. 3): Tore S. Nyerg, Die Kirche in Skandinavien. Mitceleuropäischer und englischer Einflub in 11. und 12. Jahrhundert. (Beitr. \%. (iesch. u. Quellenkunde d. Mittelahters. 10.) Sigmaringen 1986. Iür die weitere raagestellung sind hillreich: Paul R. Riamt. Ixpéditions el Pelerinage des Scandinalves en Terre Sainte. Parris 1865: Regigis Borer; Le Christ des Barbares. I e monde nordicue (IX XIIle siecle). Paris 1987: Christian Krötzel. Pilger. Mirakel und Alltag. Formen des Verhaltens im skandinavischen Mittelalter (12.-.15. Jahuthundert). (Studia Ilistorica, 46.) Helsinki 1994. Die Werke von Johannes Met-ler: Dic apostolischen Vikariate des Nordens. Paderborn 1919, und Jiar Hanste'n Kmudsen, De relationibus inter Sanctam Seden et Vorwegian. Rom 19) 4 (6. behandeln die nachrefomatorische \%cit. 
gration in das europäische Geschehen um die Mitte des 13. Jahrhunderts interessieren. Gegenüber der traditionellen Forschung zu den Beziehungen zwischen der Kurie und dem Norden ist dies eine veränderte, kulturgeschichtlich akzentuierte Perspektive.

Die Vorgeschichte dieser Beziehungen in der Mitte des 13. Jahrhunderts ist keine Geschichte eines Systems oder einer Institution, sondern die Geschichte einer Tradition, die durch einige entschlossene Männer aufrechterhalten wurde. Für Island begann diese Tradition in für uns faßbarer Weise mit dem späteren Bischof Isleif. Isleif Gizurarson war ein respektierter Isländer aus guter Familie, Priester und Familienvater in hohem Ansehen, bei denen, die ihn kannten. ${ }^{6}$ ) Isleif, zur Zeit der Einführung des Christentums in Island um das Jahr 1000 geboren, wurde mit etwa 50 Jahren von den Isländern zu ihrem Bischof gewählt und reiste dann nach einem Besuch bei Kaiser Heinrich III. nach Rom weiter. Von dort gelangte er, ausgestattet mit Privilegienbriefen, zurück zu Erzbischof Adalbert von Hamburg-Bremen. Als Metropolit des Nordens weihte ihn Adalbert rum Bischof von Island und sandte ihn mit einem Grußschreiben zurück zu den Gläubigen am Rande der bewohnbaren Welt. ${ }^{7}$ ) Isleif war durchaus vorbereitet auf seine gesamte Mission, in jungen Jahren war er Zögling der Klosterschule von Herford in Westfalen gewesen. ${ }^{8}$ )

Auf den persönlichen Kontakt kam es an. Hundert Jahre später, als der päpstliche Legat Nikolaus von Albano die kirchliche Organisation des Nordens neu strukturierte und den Erzbischof von Trondheim/ Nidaros zum Metropoliten für alle hier in Rede stehenden Gebiete machte, verpllichtete er dic künftigen Inhaber des erzbischöflichen Stubles noch einmal ausdrücklich zur persönlichen Vorstellung in

(1) Hungrvacil, in: Gudbrandur Vigfusson/l rederick York Powell (Eds.). Origines Islandicae. Vol. 1. Oxford 1905, 425-458, hier 428; vgl. zu Isleif auch Adam von Bremen, Hamburgische Kirchengeschichte III. 77 und IV. 66. Hrsg. v. Bernhard Schmeidler. (Script. Rer. Germ.) 3. Aufl. Hannover/l_eipzig 1917. Vgl. zu Isleif auch: Roland Kölue, Bischof Isleif Gizurarson. Ein berühmter Schüler des Stiftes Herford. Kirchliche Verbindungen zwischen Deutschland und Island im 11. Jahrhundert. in: Jahresber. d. HV f. d. Grafschaft Ravensburg. 67. 1970. 1-38: Otto Springer. Medieval Pilgrim Routes from Scandinavia to Rome, in: MedStud 12. 1950. 92-122.97f.

7) \% den Belegen vgl. vorangehende $\mathrm{Anm}$.; vgl. zur Christianisierung Islands auch Dag Strombarik. The Conversion of leeland. A Survey. (Viking Soc. for Northem Research, 6.) I.ondon 1975.

${ }^{8)}$ Wie Anm. 6 . 
Rom: Successores autem tui ad Romanum pontificem tantum recepturi donum consecracionis accedant..${ }^{9}$ ) Als Nikolaus nach der Rückkehr von seiner Gesandtschaft selbst als Hadrian IV. (1154-1159) den Stuhl Petri bestieg, fanden Bittsteller aus dem Norden für einige Zeit ein offenes Ohr für ihre Probleme. ${ }^{(0)}$ ) Von nun an erbaten die Erzbischöfe von Trondheim in loser Folge von der päpstlichen Kurie Hilfe gegen die Bedrückung durch ihren König ${ }^{1}$ ), suchten Entscheidungshilfe in problematischen Rechtsfragen ${ }^{12}$ ) oder erhofften sich Rückhalt gegen verheiratete Priester, die sich auf vermeintliche Genehmigungen Hadrians IV. aus der Zeit seiner Nordlandlegation beriefen ${ }^{13}$ ).

Die jeweilige Häufung einschlägiger päpstlicher Auskünfte und Entscheidungen spicgelt das Verfahren wider, bei dem ein Gesandter aus Norwegen an der Kurie vorstellig wurde und die Ansinnen vortrug. In der langen Regierungszeit König Håkons (1217-1263) wiederholten sich diese Kontaktaufnahmen regelmäßig, und es wurde eine Fülle von Problemen verhandelt. ${ }^{14}$ ) Der Papst nahm eine neugegründete Kirche in seinen Schutz ${ }^{15}$ ) und entschied in Streitereien um Begräbnisfinanzierungen. ${ }^{16}$ ) Der Schriftverkehr nahm seit der Mitte der dreißiger Jahre des 13. Jahrhunderts an Umfang zu. ${ }^{17}$ )

1) NGL I (wie Anm. 2), 440.

11) Springer, Medieval Pilgrim Routes (wie Anm. 6), 98; zu Hadrian IV. vgl. neben Almedinge'n, The English Pope (wie Anm. 2), auch Walter Ullmann, The Pontificate of Adrian IV, in: Cambridge Hist. Journ. 11, 1955, 233-252.

11) E.B Erik an Papst Clemens III.: Jacob Langebek (Id.), Scriptores Rerum Danicarum. Bd. 6. Kopenhagen 1876, ND Nendeln 1969, 19f: Creditur \& dicitur; quod sicut Eaclesiis taniversis Ecclesia Romana supereminet dignitate, sic nihilominus earum angarits \& oppressionibus patema compatitur \& subvenit pietate.

12) Philipp Jaffé, Regesta Pontificun Romanorum 2. 2. Aufl. Leipzig 1888. Nr. 12184.

1.3) DN (wic Anm. 1), Bd. I. Nr. 19.

$\left.{ }^{14}\right)$ Die politische Entwicklung Norwegens in diesen Jahren wird unten dargestellt, einführend zu Häkon, zu dessen Herrschaft es keine Monographie gibt, vgl. Knut Helle. Norge blir en stat (1130-1319). Handbok i Norges historie 3. 2. Aufl. Bergen/Oslo/Tromsï 1974, 10.3-133.

15) 1228: Gustav Storm (Fd.), Regesta Norvegica (künftig: RN). Bd. 1. Christiania 1898, Nr. 401; August Potthast (Hrsg.). Regesta Pontificum Romanorum (künftig: Potthast, RPR). Bd. I-2. Berlin 1874/75, Nr. 8244.

16) RN (wic Anm. 15), Bd. 1, Nr. 412

17) 12.34: RN (wic Anm. 15). Bd. 1, Nr. 424-4.30= Potthast, RPR (wie Anm. 15), Nr. 9712 f., $9718-9720,9723 \mathrm{f}$; 124l: RN, Bd. 1. Nr. 471-476= Pothast, RPR, Nr. 1104.5-11049; 124.3: RN. Bd. 1, Nr. 482-484= Potthast, RPR Nr. 11106 u. 11144 ; 1245: RN. Bd. 1, Nr. 485f. = Potthast, RPR, Nr. 11811 u. 11878; 1246: RN, Bd 1. 
Die Intensivierung der Verbindung gab der Kurie auch die Gelegenheit, stärker eigene Anliegen aus dem weiteren Horizont ihrer Interessen zur Geltung zu bringen, so etwa die Unterstützung gegen Friedrich II. ${ }^{18}$ ), die Aufforderung zur Hilfe für die Ungarn angesichts der tartarischen Bedrohung ${ }^{19}$ ) oder die Teilnahme an der sizilianischen Expedition Heinrichs III. (1216-1272) von England $\left.{ }^{20}\right)$.

Angesichts solcher, wohl eher ungelegener, Wünsche besannen sich dic Norweger jedoch zumeist auf ihre Randlage. Die weite Entfernung zu den Orten des Geschehens, die eigenen beschränkten Mittel sowie die Unkenntnis der Sprache stünden einer erfolgreichen norwegischen Teilnahme im Wege. ${ }^{21}$ ) Bei aller Zunahme der Kontakte - dem langen Arm des Papstes blieben doch nur sehr beschränkte Zugriffsmöglichkeiten. An eine Position der Macht, etwa im klassisch-weberschen Sinne als Möglichkeit, die Norweger auch gegen ihren Willen zur Teilnahme an kurialen Projekten oder zur Übernahme der römischen Standards, wie sie etwa im kanonischen Recht zum Ausdruck kamen, z.u bewegen, war gar nicht zu denken. ${ }^{22}$ ) Innozenz IV. war sich dessen, wie wir eingangs feststellten, durchaus bewußt. Nicht so sein

Nr. $491-501$ u. $503=$ Potthast, RPR, Nr. 12302.12330 .12339 f. $12343-12346$ u. 12348-12350; 1247: RN. Bd. 1. Nr. 516-521 u. $524=$ Potthast, RPR, Nr. 12760f.. 12782f. u. 12791: 1250: RN, Bd. 1. Nr. 539-543 = Potthast. RPR, Nr. 14119, 14121. 14129 u. 14145; /253: RN. Bd. I, Nt. 565-569 u. 576 = Ponthast, RPR. Nr. $14860,14862-14864.14895$ u. 14913; 1255: RN. Bd. 1. Nr. 581-589 = Potthust, RPR, Nr. 15732, 15735 f.. 15764. 15775, 15847 u. 15853. Die Aufstellung ist nicht vollständig, kann aber doch cinen İindruck vermitteln. Nach 1255 wird die Korrespondenz wieder sporadischer.

1x) DN (wic Anm. 1). Bd. 1. Nr. 22: RN (wic Anm. 15). Bd. 1. Nr. $467=$ Potthast. RPR (wic Anm. 15), Nr. 10946.

11) RN (wie Anm. 15), Bd. 1. Nr. 481 = Pothhast, RPR (wie Anm. 15), Nr. 11106. 20) Pothlatst. RPR (wie Anm. 15). Nr. 15841. 15843 u. 15847. \%ur politischen Linordnung s. unten.

ㄱ) Vgl. aus einer Antwort Gregors IX an König Iäkon dessen Bedenken gegen eine Kreuzaht ins Heilige Land: Cum signo vivifice crucis assumpto voreris in Terre Sance subsidium profisci, at id. sicut asseris, propter nimiam locerum distantiam of paupertatem hominam regni ata ac ignorantian linguarum interiacentiam commode nequeas adimplere ... DN (wie Anm. 1), Bd. I, Nr. 24a, vgl, auch ebd., $b$ und $c$.

22) ...Macht bedenter jede (hance. innerhath einer sorialen Beziehung den eigenen Willen auch gegen Widerstreben durchzusetzen. gleichvicl worauf diese Chance beruh"'; Max Weber; Wirtschaft und Gesellschaft. 5. Autl. T'ïbingen 1985. 28. 
Nachfolger Alexander IV. ${ }^{23}$ ) Bei ihm hat man geradezu den Eindruck, er habe die Distanz durch schrille Töne überbrücken wollen. So hatte der Auftakt eines Schreibens an den Erzbischof von Trondheim folgenden Ton:

O formidulosa speculatorum, quos populo suo dispensatio divina praeposuit, et periculosa conditio, si praesumtorie res agatur; si eo modo in sollicitudine commissa non militent, quo summus praecepit Imperator, si sibi et universo gregi, cui Deus eos custodes et episcopos constituit, non attendant, hiis praecipue horrendum erit illud humanorum operum finale judicium omnibus in commune tremendum, in eo etsi unusquisque proprii de corporis actionibus districto sit subjiciendus examini, ut recipiat prout gessit ... ${ }^{24}$ )

So ging es noch viele Zeilen weiter. Auch das war eine Strategie. Sie machte den Norwegern deutlich, daß es um etwas wirklich Wichtiges ging. Das tat es auch. Es ging um das hartnäckige Hochzeitsverhalten ihrer Priester. Der disziplinierende Eindruck, den solch apokalyptische Mahnungen hervorriefen, wird gleichwohl verhalten gewesen sein. Der Grundsaty tatsächlicher Autorität, der in Teddy Roosevelts Formulierung ,..speak softly and carry a big stick" in die historische Sentenzensammlung einging, entsprach nicht Alexanders Temperament. ${ }^{25}$ )

Dies war allerdings mehr eine Frage des persönlichen Stils. Die schlichte Grundsituation war die. daß die Kurie in der Erzdiözese Trondheim um die Mitte des 13. Jahrhunderts keine Direktiven durchsetzen konnte, ohne daß diese von den Norwegern. Isländern und Grönländern mitgetragen worden wären. Interessant dabei ist, wie schr die Christen am Rande der bewohnbaren Welt überhaupt die Entscheidung der Kurie einholten. Es hatte auf Island in der frühen Phase der christlichen Geschichte durchaus dubiose Bischöfe gegeben, die den Menschen ein weniger strenges Christentum angeboten hatten ${ }^{26}$ ), nun aber bemuihte sich die norwegische Kirche in ihren Anfragen selbst um die römischen Standards, und sie lat dies verstärkt in einem gesellschaftlichen Umfeld, das sich curopäischen Einflüssen öfnete.

Dic Frage, die es daher im folgenden zu untersuchen gilt, lautet: In welchem 7usammenhang vollzog sich diese freiwillige Übernahme

23) Vgl. zu Alexander IV.: Fram Tenckhoff, Papst Alexander IV. Paderborn 1907: Johames Haller, Das Papsttum. Ba. 4. 2. Aufl. Stuttgart 1952. 272-296.

2.) Diplomatarium Istandicum (künftiğ: J)1). Bd. I. Kaupmannahöfn 18.57-1876. .ir. 151 .

25) Elting E. Morisen (Fid.). The Lcters of Theodore Roosevelt. Vol. 2. Cambridge. Malss. 1951. Nr. 1456. S. 1141.

26) Hungrvaca (wie Anm, 6), 429. 
von Normen, die unter den Bedingungen einer anderen Lebenserfahrung entwickelt worden waren?27) Wir werden feststellen, daß es sich bei der Intensivierung der Kontakte um eine Bewegung handelt, die nicht nur beim Klerus festzustellen ist, sondern in vielen und zentralen Bereichen der norwegischen Gesellschaft.

Die Norweger hatten wichtige Anliegen in Rom vorzutragen. Ein solches Ansinnen der norwegischen Kirche war die Heiligsprechung von Erzbischof Eysteinn (August) von Trondheim (1157-1188), dem Begründer der Kathedrale des damals neuerrichteten Erzbistums. ${ }^{28}$ ) Eine Provinzialsynode hatte in Trondheim 1229 über Eysteinns Heiligsprechung beraten ${ }^{29}$ ), und in den folgenden Jahrzehnten kam es immer wieder zu Verhandlungen mit der Kurie über die Kanonisation, allein es wurde zu Håkons Zeit nichts daraus ${ }^{30}$ ).

In etwa diesen Jahren ging noch ein anderes Ersuchen aus Norwegen an der Kurie ein, das dem Antragsteller ebenfalls einige Geduld abverlangte. König Håkon wünschte für sich eine erneute Krönung durch einen päpstlichen Legaten. Der Ausgang des Verfahrens belohnte sein stetes Bemühen. Das Projekt ist 1229 erstmals in den Quellen faßbar, war aber noch älter. Denn im Jahr 1229 hatte Gregor IX. dem Erzhischof von Trondheim und dem Bischof von Bergen über dieses An-

27) Vgl. zu diesem Problem auch meinen parallel erscheinenden Beitrag zur liturgischen Normierung in Norwegen in: ZRG KA 83, 1997, mit weiterer Literatur.

28) Zu Erzbischof Eysteinn Erlendsson gibt es nur wenig Literatur; einen knappen Überblick gibt Sverre Bagge, Art. .,Eysteinn Erlendsson", in: Lexikon des Mittelalters. Bd. 4. München/Zürich 1989. $193 \mathrm{f}$.

29) Vgl. das ausführliche Regest: DI (wie Anm. 24), Bd. 1, Nr. 134; Konrad Maurer, Norwegens Schenkung an den heiligen Olaf. (Abh. d. kgl. bayr. Akad. d. Wiss., Philos.-Philol. Klasse. 14/2.) München 1877, 81.

30) DN (wie Anm. 1), Bd. 1, Nr. 23 (1243) = Potthast, RPR (wic Anm. 15), Nr. $11005 ;$ DN, Bd. 6/1, Nr. 23 = Potthast, RPR, Nr. 14151 (1251); DN. Bd. 6/1, Nr. 30 $=$ Potthast, RPR, Nr. 15775 (1255); Annales ccclesiastici ad 1268. \& 48. Bd. 22. Bar-le-duc 1870, $2341 .$. ... variis tamen impedimentis, et obstaculis interim occurentibus, inquisitionis ipsius negotium remansit usque ad haec tempora imperfectum. Fysteinn wurde nie von der Kuric kanonisiert und blich so ein ,inoffizieller Heiliger" in Norwegen; vgl. Ludvig Daue. Norgenes Helgener. Christiania 1879. 175. Bei Pius Bonifatius Gams (Hrsg.), Series Episcoporum Ecclesiae Catholicae. Regensburg 1873, 35.5, firmiert Eysteinn als ...sinctis adscriptus". Vgl. zu dem Thema zulet/t auch Erich Hoffmamn. Politische Heilige in Skandinavien und die Entwicklung der drei nordischen Reiche und Völker, in: Jürgen Petersohn (Hrsg.), Politik und Heiligenverehrung im Hochmittelalter. (VuF. 42.) Sigmaringen 1994 , 277--324, 320. 
sinnen ihres Königs Håkon geschrieben: ... cum ipse olim super coronatione sua nobis attentius supplicasset. ${ }^{31}$ )

Håkon war ein illegitimer Enkel des bedeutenden norwegischen Königs Sverri ${ }^{32}$ ), und er konnte seinen Anspruch auf die alleinige Herrschaft in Norwegen erst nach einem Jahrzehnte währenden Konflikt durchsetzen. Es war ihm 1217 zunächst gelungen, die mächtigen und skeptischen Männer seines Landes davon zu überzeugen, daß er tatsächlich der Sohn des Königs Håkon war, und sie zu seiner Königswahl zu veranlassen. ${ }^{33}$ ) Mit einer archaischen Eisenprobe gelang es seiner Mutter schließlich, auch den Erzbischof von Trondheim von Håkons königlicher Abstammung $\mathrm{zu}$ überzeugen. ${ }^{34}$ ) Dennoch mußte Håkon seinem mächtigen Gegenspieler, dem Herzog (Jarl) Skuli, einen erheblichen Anteil an sciner Herrschaft zugestehen. ${ }^{35}$ ) Das unklare Verhältnis der beiden bestimmte auf lange Jahre die innere Entwicklung Norwegens. Spannungen und Versöhnungen lösten sich ab, und die Frage der eigentlichen Königsmacht stellte sich stets aufs neue. ${ }^{36}$ ) In dieser Situation hoffte Håkon, den Makel sciner Geburt durch eine Sanktionierung von höchster christlicher Autorität aufwerten zu können. So wie cin halbes Jahrtausend vor ihm der Karolinger Pippin eine Stärkung seiner Herrschaft im Bündnis mit dem Papsttum suchte, so wandte sich auch Håkon nun nach Rom, um von dort eine Aufwertung seines Königstitels 7.u erlangen. ${ }^{37}$ )

So weit aber mußte ein norwegischer König nicht zurückblicken, denn es gab ein näherliegendes Vorbild in Norwegens Königsgeschichte. Im Jahre 1164 war in einer ähnlichen Gemengelage aus erbittertem Bürgerkrieg schließlich als aussichtsreichster Kandidat für den

3) IDN (wie Anm. 1), Bd. 1, Nr. 11.

32) Gudbrandur Vigfusson (Ed.). Hakonarsaga. (RS-Icelandic Sagas, 2.) London 1887, Kap. 1 u. 3: eine englische Übersetzung des altnordischen Textes in derselben Reihe: The Saga of Hacon. Transl. by Ceorge Webbe Dasent. (RS-Icelandic Sagas, 4.) L.ondon 1894. Dic Kapitelaufteilung ist identisch. Vgl, zu Håkons Herkunft auch: Helle, Norge (wie Anm. 14). 105-108.

3.2) Vigfusson (Ed.), Hakonarsaga (wie Anm. 32), Kap. 12-17 u. $23 \mathrm{f}$.

.34) Ebd. Kap. 39 u. 41-46; vgl. auch Zom, Stat und Kirche (wie Anm. 2), $155 \mathrm{f}$.

35) Vgl. ctwa Vigfusson (Ed.), Hakonarsaga (wie Anm. 32), Kap. 24.

36) Vgl. cbd. Kap. 80, 174-177, 181, 185.

i7) Zu Pippin: Annales regni Francorum ad a. 749/750. Hrse. v. Georg Heinrich Pertz u. Friedrich Kurze. (Script. Rer. germ.) Hannover 1895. ND) 1950. 8-11; 7u Häkons Krönungsgesuch: I)N (wie Anm. 1), Bd. 1, Nr. 11 (1229) U. 12 (1231). 
norwegischen Thron Magnus Erlingsson hervorgegangen. ${ }^{38}$ ) Magnus aber stammte nicht aus einer königlichen Familie, was beim Erzbischof von Trondheim zunächst erheblichen Widerstand hervorrief. ${ }^{39}$ ) Der Bischof war eben jener Eysteinn gewesen, dessen Kanonisierung der norwegische Klerus nun parallel zu Håkons Krönungsersuchen betrieb. Darin konnte man durchaus eine Spitze gegen das norwegische Königtum sehen, denn Eysteinn war dem Königskandidaten 1164 sehr energisch gegenübergetreten. ${ }^{40}$ ) Eysteinn hatte, der Gründungsurkunde seines neuen Erıbistums folgend, sein Pallium wohl in Rom von Alexander III. erhalten. ${ }^{41}$ ) Aus Rom hatte cr offenbar einiges von dem entschiedenen kurialen Selbstbewußtsein vor Herrscherthronen mitgebracht, denn es gelang ihm, den jungen König auf eine Thronfolgeregelung zu verpflichten, die dem Erøbischof für den Fall, daß der König ohne geeigneten Sohn stürbe, eine entscheidende Rolle bei der Bestimmung eines Nachfolgers einräumte. ${ }^{42}$ ) Damit hatte die norwegische Kirche aus einer momentanen Bedrängnis des Königtums zunächst ein erhebliches Zugeständnis erlangt. Bei der Krönung war nun auch ein päpstlicher Legat anwesend, ohne daß wir von seiner Aufgabe eine genauere Vorstellung hätten. ${ }^{4.3}$ )

38) Helle. Norge (wic Anm. 14), 53-60.

i") Fbd.; vgl. auch: Zorn. Staat und Kirche (wic Amm. 2). 98-103: Maurer; Norwegens Schenkung (wie Anm. 29), 7,5-77.

4i) Fbd. Vgl. auch Zorn. Staat und Kirche (wie Anm. 2), 103-109.

+1) Maner, Norwegens Schenkung (wic Anm. 29), 75f.; Seegriön, Das Papstum (wie Anm. 2), 184 mit Anm. 291: Werner Ohnserge, Päpstliche und gegenpäpstliche Legaten in Deutschland und Skandinavien 1159-1181. (Historische Studien, 188.) Berlin 1929, 90 f.

12) Gulathingslög. Kap. 2: Norwegisches Recht. Das Rechtsbuch des Gulathings.

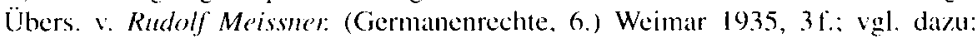
7orn, Staat und Kirche (wie Anm. 2), 103-109); Matre'; Norwegens Schenkungr (wic $\Lambda$ mm. 29). diskutient in dem gesamten Beitrag ausfïhrlich die Überlicferung und ihren Gehalt; Seegriom, Das Papstlum (wie Anm. 2). 183-194, gibt eine cigene Deutung. scheint abor die ältere Diskussion gar nicht zu kennen. Vgl. zur Stellung des norwegischen Königs zur Kurie auch Holtzmam, Krone und Kirche (wie Amm. 4). und Johannes fried, Der päpstliche Schuty für Laienfürsten. Die politische Geschichte des päpstlichen Schutzprivilegs für I aajen (11,-13.Jh.). (Abh. d. Heidelberger $A$ kad. d. Wiss., Philos.-hist. Klasse. 1.) Heidelberg 1980, $1.35 \mathrm{f}$.

4.3) ... et Magnus coronaturs est et intunctus in regem, secundo amo regni sui, et quinto anno aetatis suac'; ante cujus consecrationem non legitur aliquem alium fuisse in regho Norwegiae in regem consectatum: anmo scilicet quarto papatus Alexandri papae tertii, magistro Stephano de Urbe Veteri misso illuc legato: Benedict of Peterborough. Gesta Regis Heinrici Secundi 1. Ed. William Stubbs. London 
Dem König Magnus und auch dem Erzbischof half die päpstliche Salbung nicht lange. Die Führung der gegnerischen Partei übernahm in den folgenden Jahren jener bereits erwähnte Sverri, der Magnus vom Thron und den Erzbischof aus dem Lande trieb. ${ }^{44}$ ) Nachdem der Erzbischof von Trondheim die Schwäche der Königsmacht zugunsten des kirchlichen Einflusses genutzt hatte, setzten nun unter Sverri - dem „personifizierten Konflikt mit der Kirche" ${ }^{\text {"45 }}$ ) - Jahre heftiger Gegenreaktion ein. ${ }^{46}$ ) Auch dic Kirche hielt sich nicht zurück und begegnete dem Angriff mit dem ausführlichen Einsatz des Kirchenbannes. Besonders seit dem Amtsantritt Innozenz' III. (1198) erhielt der Erzbischof von Trondheim römische Unterstützung. ${ }^{47}$ )

Interessant für unsere Frage nach der Haltung der Norweger zur Kurie ist ein aus diesem Konflikt hervorgegangenes Pamphlet eines königsnahen, unbekannten Verfassers aus der Zeit um 1200, die sogenannte „Oratio contra Clerum Norvegiae“.48) In scharfer Form greift die Schrift, dic ausführlich mit kirchenrechtlichen Zitaten, v. a. aus dem Decretum Gratiani, argumentiert, das Verhalten der Kirche, besonders den Einsaty der Exkommunikation. an. Die Kirche pervertiere damit ihre eigentliche Aufgabe. Es ist aufschlußreich für die Frage nach dem paipstlichen Einfluß, daß der Autor den Papst und die Kardinäle von ciner eigenen Verantwortung freispricht und dic Informationspolitik der Bischöfe als Ursache des Übels ansieht. Er diskutiert auch ausführlich

1867. ND 1965 (RS 49). 267 f: vgl. dazu Ohnsorge. Päpstliche Legaten (wie Anm. 41). 92-101. Der Legat hatte aber wohl in erster Linie eine seelsorgerische Mission: ebd. 96.

4.) Benedict of Peterborough, Gesta I (wic Anm. 43), 268f.: Zom, Staat und Kirche (wie Anm. 2), 111-121: Helle, Norge (wic Anm. 14). 74-90.

45) Zorn, Staat und Kirche (wie Anm. 2), 118.

th) Der Konflikı Sverris mit der Kirche soll un!s hier nicht ausführlicher beschältigen. Die aufschlußreichste Quelle ist die Saga des Königs: Gustur Indreboj (Kd.), Sverris-Saga. Oslo 1920, ND Oslo 1981; eine englische Übersetzung bietet: John Sephton. Sverrissaga: The Saga of King Sverri of Norway. (Northern I ibrary. 4.) [.ondon 1899: vgl. aulierdem \%om. Stat und Kirche (wic Anm. 2), 11]-149.

17) Vgl. die verschiedenen Breven Innozenz' 111.: DN (wie Anm, 1), Bd. 6/1, Nr. 6f:. dazu Kom, Statat und Kirche (wic Anm. 2), 133-145.

4*) Anme Holtsmark, Fin tale mot biskopene. Fin sproglik-historisk undersökelse. (Skrilter utgitt as det norske vitenkaps-alkademi i Oslo, Hist-filos. KI. 1930, 9.) ()slo 1930 - mit ciner Fdition des Textes. Fine ältere Edition des altnordischen Texis mit ciner latcinischen Übersetzung hat Lirh Christion Werlauff vorgelegt: Anecdoton Historiam Sverreri. Kopenhagen 1815: vgl. dazu Erik (iummes. Kongens aere. Kongemakt og Kirke i ..Ln tale mot biskopene". Oslo 1971. 
die Frage, ob eine päpstliche Entscheidung zu befolgen sei, falls sie ungerecht sei, und er kommt zu einer klaren ablehnenden Antwort. Wir wollen hier auf die weitere Argumentation dieses interessanten Textes nicht eingehen, da sie zu einem anderen Thema führt. Es sei nur so viel festgehalten, daß auch dieser Text das bisherige Ergebnis stützt, das den päpstlichen Sanktionsmöglichkeiten in Norwegen enge Grenzen setzt.

König Håkon führte den Konflikt in seiner Regierungszeit nicht fort und belebte ihn auch nicht neu. Daß er sowohl eine Unterstuitzung aus Rom erhoffte als auch einen versöhnlichen modus vivendi mit den $\mathrm{Bi}$ schöfen seines Landes suchte, wird in besonderer Weise darin deutlich, daß 1241 gemeinsam mit dem Erzbischof von Trondheim und dessen Suffraganen in Rom die Kanonisierung Erzbischof Eysteinns erbat. ${ }^{49}$ ) Håkons Politik cines gesellschaftlichen Konsenses ermöglichte Norwegen eine überaus fruchtbare Phase seiner mittelalterlichen Geschichte. ${ }^{50}$ ) Im Gegenzug bat nun auch der Erzbischof von Trondheim im Frühjahr 1241 um die päpstliche Erlaubnis, Håkon zum König salben zu dürfen. ${ }^{51}$ ) Damit erhofften sich die zentralen Institutionen der norwegischen Gesellschaft, der König und der Klerus, in einem gemeinsamen Vorgehen eine Festigung ihrer Position durch die Unterstiitzung aus Rom.

In Rom hatte sich dic Lage unterdessen dramatisch zugespitzt, und während Gregor IX. angesichts der früheren Anfragen Håkons keinen unmittelbaren Handlungsbedarf gesehen hatte, ähnelte seine Situation nun doch zunehmend der seiner Vorgänger Zacharias und Stephan, die ihrerseits dic Hilfe des Karolingers Pippin gesucht hatten. ${ }^{52}$ )

Gregor IX. hatte nach langjährigen Konflikten und zwischenzeitlicher Versöhnung Kaiser Friedrich II. am Gründonnerstag 1239 exkommuniziert. ${ }^{53}$ ) Es begann nun ein crbitterter Kampf. Mit seinen Truppen

49) DN (wie Anm. 1), Bd. 1, Nr. 23. Zu ciner allgemeinen Finschätzung von Häkons Politik gegenüber der Kirche vgl. Zom, Staat und Kirche (wie Anm. 2), 155198, und Helle, Norge (wic Anm. 14), 111-118.

50) Vgl. etwa Birgit Sanver/Peter Sanver, Medieval Salindinavia. (The Nordic Series. 17.) Minneapolis/London 1993, 63: „By the middle of the thirteenth century Norway had emerged from the prolonged period of civil wars as the most stable of the scandinavian kingdoms."

51) DN (wie Amm. 1). Bd. 1. Nr. 25.

52) Wie oben Anm. 37.

53) Georg Heinrich Perte (Hrsg.). Annales Stadenses ad a. 1239. (MGH Script., 16.) Hannover 1859. 363f.; Potthast, RPR (wic Anm. 15), Bd. 2. 908 (24. Märt); 
schloß Friedrich den alten Papst in Rom ein, um ihn zum Einlenken zu zwingen. ${ }^{54}$ ) Am 9. August 1240 rief Gregor IX. europäische Könige und Prälaten zu einem allgemeinen Konzil nach Rom, das an Ostern 1241 stattfinden sollte. ${ }^{55}$ ) Friedrich sah wohl die Gefahr, die von einem solchen Konzil für ihn ausging, und er warnte ausdrücklich vor dem Besuch. ${ }^{56}$ ) Gregor wiederholte die Einladung im Oktober ${ }^{57}$ ), diesmal wurde auch der Erzbischof von Trondheim geladen ${ }^{58}$ ). Der Ostertermin nahte und verstrich, ohne daß das Konzil zusammengetreten wäre. Friedrich kontrollierte die Straßen nach Rom, und so entschloß man sich schließlich, die Prälaten über den Hafen von Genua und die genuesische Flotte einzuschiffen. Das Verfahren war gefährlich, und es schlug fehl. Am 3. Mai wurden die Schiffe von Friedrichs Flotte aufgebracht, nur wenige entkamen. Viele der Prälaten gingen in Gefangenschaft, manche für viele Jahre. ${ }^{59}$ )

Die Norweger aber gelangten nach Rom, und damit ereignete sich geradezu symbolhaft die Integration ihrer eigenen wichtigen Anliegen in die dramatische Entwicklung der europäischen Geschichte jener Jahre: Die Bitten um die Heiligsprechung des Gründers der Kathedrale von Trondheim und um die Krönung König Håkons wurden Gregor IX. von der norwegischen Delegation vorgetragen, die aus Anlaß des Konzils nach Rom gereist war. Sie traf in der Sommerhitze Roms auf cinen alten Papst, der sich den Umständen nicht ergab, sondern bereit war, ungebeugt zu sterben. Als die Delegation wieder in Trondheim eintraf,

vgl. zur gesamten Geschichte des Kamptes: Emst Kantorowica. Kaiser Friedrich der Zweite. Berlin 1927, 418-512 (Friedrich II. - Gregor IX.). 512-6.32 (Friedrich II. - Innozenz IV.); Johannes Haller; Das Papsttum (wie Anm. 23). Bd. 4, 114-148 (Gregor IX.). 148-242 (Innozenz IV.).

54) Vgl. etwa Haller. Das Papsttum (wie Anm. 23), Bd. 4, 138-148.

55) Text der Einladung z. B. bei Jean Louis Alphonse Huillard-Bréholles (Ed.). Historia diplomatica Friderici secundi 5.2. Paris 1959. 1020: Quia igitur grandes apostolic' sedis eventus et causas te ignorare non convenit ...: die verschiedenen Adressaten: Potthast. RPR (wic Anm. 15). Nr. 10925-10931.

57) Ludwig Weiland (Hrsg.). MGH Constitutiones et Acta publica. Bd. 2. Hannover 1896. Nr. 233.

57) Georg Heinrich Pert: (Hrsg.). Epistolae saeculi XIII. Bd. 1. Berlin 1883. Nr. 785, S. 692.

58) Ebd. S. 691; Potthast. RPR (wic Anm. 15), Nr. 10946.

50) Bericht spanischer Prälaten: Pertz (Hrsg.), Epistolac sacculi XIII (wie Aum. 57), Nr. 812: des Podestà von Genua, cbd. Nr. 813; vgl. auch Haller, Dats Papsttum (wie $\wedge$ nm. 23), Bd. 4, 142-146. 
war Gregor IX. bereits tot $\left.{ }^{60}\right)$, und schon bald sollte sich für die Norweger erweisen, daß ihre eigenen Bemühungen um die kuriale Aufmerksamkeit auf verstärktes Interesse stießen. Der Konflikt des Staufers mit Innozenz IV. sollte in den kommenden Jahren wesentliche Auswirkungen auf die norwegische Position in Europa haben.

Dabei suchte Norwegens König nicht nur die Unterstützung der Kurie, sondern er unterhielt schon seit langen Jahren gute Beziehungen zu Kaiser Friedrich. Dieses gute Einverständnis mag auch ein Grund dafür gewesen sein, daß die norwegische Delegation überhaupt nach Rom gelangt war und daß die norwegischen Prälaten nicht das Schicksal vieler ihrer gefangenen Mitbürger teilen mu(3ten. ${ }^{61}$ ) Schon bald nach dem Amtsantritt Innozenz' IV. wandte sich Håkon an den neuen Papst, um seine Bitte um die Krönung erneut vorzutragen. ${ }^{(62)}$ Diesmal war die Gesandtschaft erfolgreich, und Innozenz IV. versprach, einen Kardinal zur Krönung zu entsenden. ${ }^{63}$ ) Hăkon machte sich ungesäumt daran, einen feierlichen Empfang und die Krönungsfestlichkeiten vorzubereiten. ${ }^{64}$ ) Ende Oktober 1246 teilte ihm Innozenz die Entsendung eines Kardinallegaten durch ein überliefertes Schreiben mit. ${ }^{65}$ )

Der Gesandte war Kardinal Wilhelm von Sabina. ${ }^{66}$ ) In seiner Person kommt das Zusammentreffen von originär seelsorgerlichen und kirchlichen Zielen mit dem großen politischen Konflikt zwischen Kaiser Friedrich und der Kurie, das nahezu alle weiterreichenden kirchlichen

(ii) Gregor IX. starb am 22. August 1241: Potthast, RPR (wie Anm. 15). Bd. 1, 937. Füir die Daluer der Reise von Rom nach Trondheim wird man um die 50 Tage veranschlagen müssen. Ein norwegischer (jesandter hatte 1225 für eine dringliche Mission etwa diese Zeit benötigt: Springer, Medieval Pilgrim Routes (wie Anm. 6). 122.

(1) Die Hakonarsaga (wic Anm. 32), Kap. 191. spricht zum Jahr 1237 von ciner lange bestehenden Freundschaft zwischen Hăkon und Friedrich und zählt die zahlreichen Gesandtschatten zwischen den beiden Herrschern auf, ohme sie allerdings präziser zu datieren.

(12) Diese Kontaktaufnahme ist nur durch die Hakonarsaga (wie Anm. 32). Kap. 246-248. überliefert. Sie ist nicht präziser zu datieren. da der Autor gerade an dieser Stelle - Kap. 246 - cin ctwas verwickeltes Stück relativer Chronologie bictct. Ihre Einordnung in den chronologischen Strang der Erzihlung ist jedoch klar, und die weiteren Kontakte sind auch genauer zu bestimmen.

(1.) Fibd. Kap. 248.

(it) Ebd.

(15) DN (wie Anm. 1). Bd. 1. Nr. 30=Potthast, RPR (wie Anm. 15), Nr. 12330) vgl. auch DN, Bd.I. Nr. 31 f.

(1i) Ebd. 
Projekte dieser Jahre auszeichnete, geradezu exemplarisch zum Ausdruck. Wilhelm war ein Mann, der den kurialen Kampf mit Friedrich II. unmittelbar miterlebt hatte und der gleichzeitig ein wirklicher Spezialist für seine Legation in den Norden war ${ }^{67}$ ) Er war seit seinem ersten Auftreten als päpstlicher Vizekanzler um $1220^{68}$ ) zu einem wichtigen Mann an der Kuric geworden, und am 28. Mai 1244 zählte er zu den ersten Prälaten, die Innozenz IV. zu Kardinälen erhob. ${ }^{69}$ ) Ein Jahr später war er im Gefolge von Innozenz, als dieser mit dem Schiff nach Genua entkam. ${ }^{70}$ ) Nun erhielt er mit der Legation zur Krönung Håkons noch einmal eine beschwerliche Aufgabe. Diesmal galten seine Vollmachten für Norwegen und Schweden. ${ }^{71}$ )

Der Kardinal reiste über England und folgte damit einer üblichen Route für die Reise zwischen Rom und Norwegen. ${ }^{72}$ ) Er nutzte wohl die Gelegenheit auch zur eigenen Alimentierung. ${ }^{73}$ ) Entrüstet schildert Matthäus Parisiensis, der Benediktiner aus St. Albans, die üppige Ladung von Wilhelms Schiff beim Aufbruch nach Norwegen - quam opulentissime communiverat multo frumento et doliis quam plurimis vino plenis praeelecto et aliis victualibus..${ }^{7+}$ ) Aber wer wollte es dem ar-

$\left.{ }^{67}\right)$ \%u Wilhelm vgl. besonders die gründliche Biographie von Domner Kardinal Wilhelm (wie Anm, 5); auch das Hauptaugenmerk von Estrup, Idea Hierarchiate Romanae (wic Anm. 5), gilt Wilhelms Legation und Tatigkeit in Norwegen.

${ }^{6}$ ) Harry Bresstau. Handbuch der Urkundenlehre. Bd. 1. 2. Aufl. Leipzig 1912 , 250: vgl. dazu Donner: Kardinal Wilhelm (wic Anm. 5), 12-17.

(19) Conrad Eubel (Hrsg.). Hicrarchia Catholical Medii Aevi 1. 2. Aufl. Münster 1913.7.

71) Nicolaus de Curbio, Vita Innocenti IV, cap. 13 ed. Alberto Melloni, in: ders., Innocenzo IV. La concezione e l'esperienza della christianità come regimen unius personte. (Genuai 1990. Append. 250-293, 266.

71) DN (wie Anm. 1). Bd. I. Nr. 31 = Potthasl. RPR (wie Anm. 15), Nr. 12339 und auch 12349 .

72.) Vgl. Springer: Medicval Pilgrim Routes (wic Anm. 6), 100--104.

7.) Mathatei Parisiensis. Chronica majora (künftig: (CM) 4. Ed. Henry Richards Luard. London 1877. ND) 1964. (RS), 626. Matthius berichtet empört daruber. wie der Legat wihrend seines fast dreimonatigen Aufenthaltes vom englischen Klerus Unterstittung im Wert von 4000 Mark eingefordert habe. Allerdings war die tinanzielle Ausbeutung Fnglands durch die Kurie Matthäus" ureigenstes Anliegen. das sich durch sein gesantes Werk zicht.

74) Mathäus P'atisiensis. CM 4 (wic Anm. 73). 627. \%u Matthäus vol.: Richard Vaughan, Matthew Paris. Cambridge 1958: Karl Schmith. Fngland in einer sich wandeInden Welt (1189-1259). Sudien zu Roger Wendover und Matthäus Parisiensis. (Monographien /. Gesch. d. Mittelalters. 7.) Stuttgan 1974: Antonia (Framsden, Historical Writing in Fingland c. 550 to 1307. I.ondon 1974. 365-379. 
men Mann verdenken, hatten doch die Engländer selbst ihn vor der Reise gewarnt und vor den bedrückenden Aussichten inmitten dieses wilden Volkes, wo es kaum Fleisch zu essen gäbe und nur vergorene Milch zu trinken - wie Wilhelm, überrascht durch den großherzigen und zivilisierten Empfang, seine norwegischen Gastgeber nach der Ankunft wissen ließ..$^{75}$ )

Auf den Legaten wartete einige Arbeit. War das Verhältnis Håkons zum Klerus seines Landes auch deutlich ausgeglichener als unter seinen Vorgängern, so bot doch ein entsprechender Anlaß wie die kirchliche Krönung des Königs dem Erzbischof von Trondheim die Gelegenheit, schon länger ruhende Maximalforderungen erneut zu Gehör zu bringen. Erzbischof Sigurd hatte bereits im Zusammenhang mit Håkons letzten Krönungsersuchen bei Innozenz IV. weitere kirchliche Privilegien beansprucht und vom König verlangt, er solle denselben Krönungseid leisten, den sein Vorgänger Magnus gegenüber Erzbischof Eysteinn abgelegt habe. Håkon hatte dieses Ansinnen mit deutlichen Worten zuruickgewiesen. ${ }^{76}$ ) Die Ankunft des Legaten bot daher dem Ersbischof die Gelegenheit zu einem erneuten Versuch der Verknüpfung seines Anliegens mit der Krönung, allein der Kardinal ließ sich durch Håkon von der Ungehörigkeit der Forderung überzeugen. ${ }^{77}$ ) Es gab noch andere Fragen zur rechtlichen Stellung der norwegischen Kirche, deren Regelung auf einer Synode angestrebt wurde. ${ }^{78}$ ) Das wenige. das wir dabei in den Quellen klar fassen können, vermittelt den Eindruck, daß Norwegen in der Entwicklung mancher Problemlagen dic wir hier cinmal als Indikator des Entwicklungsstandes ansehen wollen - durchaus mitteleuropäischen Standard erreicht hatte. So hatte der Legat einen Streit zwischen den Dominikanern in Bergen und den be-

75) Hakonarsaga (wie Anm. 32). Kap. 249.

71) Ebd. Kap. 247; vgl. dazu Kom, Staat und Kirche (wie Ann. 2), 1651.

77) Hakonarsaga (wie Anm. 32), Kap. 251: Zorn, Staat und Kirche (wie Anm. 2). 1831; Donner, Kardinal Wilhelm (wie Anm. 5), 325-329.

78) Die erhaltenen Urkunden: DN' (wic Anm. 1), Bd. 2. Nr. 71.; DN, Bd. 8/1, Nr. 6; DN, Bd. 1, Nr. 140; vgl. auch: Hakonarsaga (wie Anm. 32), Kap. 255; dazu etwa 7om. Staat und Kirche (wic Anm. 2), 184-194; Donner. Kardinal Wilhelm (wie Anm. 5). 335--355. Die in der Literatur diskutierte Frage, inwieweit der Legat bei dieser Gelegenheit dem Einfluß des kanonischen Rechtes Vorschub leistete, ist natürlich für unsere Frage nach Norwegens Integration in das kirchliche Normensystem von erheblicher Bedeutung. Die Quellengrundlage, die uiber die vier erhaltenen Urkunden kaum hinausgeht. lïdt aber eher zu Spekulationen ein, als daß sie klare Schlüsse erlaubt. Daher streife ich das Thema an dieser Stelle nur. 
nachbarten Kanonikern des Domstiftes zu schlichten, den die Stiftsherren mit rüden Mitteln geführt hatten. Damit stand der Norden in einer Konfliktlinie, die ein dringendes kirchliches Thema des europäischen Kernbereichs darstellte. ${ }^{79}$ ) Diesen Regelungen vorausgegangen war jedoch das Ereignis, um dessentwillen Kardinal Wilhelm den weiten Weg gereist war: die Krönung Håkons am Tag des Hl. Olaf, dem 29. Juli, 1247 in Bergen. ${ }^{80}$ )

Ein bedeutendes Publikum war $z u$ der Zeremonie gekommen: neben dem König und seinem Sohn, dem Kardinallegaten und dem Erzbischof von Trondheim auch dessen norwegische Suffragane, viele der mächtigen Männer des Landes und eine Zahl von Prälaten. ${ }^{81}$ ) Nach der feierlichen Krönung hob eine mehrtïgige Feier an. Der Kardinallegat nutzte die Gelegenheit zu einer kurzen Ansprache, in der er noch einmal die besondere Ehre hervorhob, die Håkon durch die Krönung zuteil geworden sei. ${ }^{82}$ ) Noch cinmal unterstrich er seine Freude über den gastlichen Empfang und über die Sitten des Landes. Interessant aber ist neben diesen durchaus zu erwartenden Bekundungen für die Frage der norwegischen Einbindung in das europäische Geschehen besonders, was der weitgereiste Kardinal über das Handelsniveau zu sagen hatte. Was er in Norwegen vorfinde, so fuhr er nämlich fort, strafe alle diejenigen Lügen, die ihm die Wildheit der Menschen und die Kargheit des Landes so drastisch geschildert hätten. Statt dessen finde er in Bergen eine solche Menge von Schiffen im Hafen, wie er es niemals zuvor in anderen Häfen gesehen hätte - beladen mit allerlei reichen Gütern. Es seien auch viele Menschen aus anderen Ländern in der Stadt - der Kardinal war beeindruckt. ${ }^{8.3}$ ) So waren die Krönung und ihr Umfeld ein

70) DN (wie Anm. 1). Bd. 2, Nr. 7; zum Thema allgemein: Camill Patus, Welt und Ordensklerus beim Ausgang des 13. Jahrhunderts im Kampf um die Pfarrechte. Diss. phil. Göttingen I90().

80) Fine eingehende Schilderung der Feicrlichkeiten in der Hakonarsaga (wie Anm. 32), Kap. 252 255; vgl. Donner; Kardinal Wilhelm (wie $\Lambda$ nm. 5), 330-332. Zu Bedeutung des Hl. Olaf für das norwegische Königtum vgl. Erich Hoffmam, Die heiligen Könjge bei den Angelsachsen und den skandinavischen Völkern. (Quellen u. Forsch. z. (iesch. Schleswig-Holsteins, 69.) Neumünster 1975, 58-88. 81) Hakonarsaga (wic Anm. 32), Kap. 253.

8) Khd. Kap. 25.5.

8.) Fbat. Kap. 255; Donner, Kardinal Wilhelm (wic Anm. 5). 332. weist mit Recht daraul hin, daß Wilhelm aus Itatien und von seinen bisherigen Legationen her eine Reihe bedeutender Handelsstidte zum Vergleich heranzichen konnte, wie elwa Genui, Dover und l uibeck. 
augenfälliger Beleg für den erfreulichen Zustand des Landes selbst und auch für seine Einbindung in die Handels- und die kirchlichen Strukturen Europas.

Das Bemühen der Einbindung erschöpfte sich aber nicht auf diesen beiden Feldern, sondern die Krönung bot auch Anlaß, Norwegens König auf die Höhe der politischen Konflikte Europas zu bringen. Denn anläßlich der Krönung als norwegischer König hatte Kardinal Wilhelm Håkon die päpstliche Anfrage übermittclt, ob er auch die Kaiserkrone tragen wolle. ${ }^{84}$ ) In weiser Einschätzung seiner Mittel hatte Håkon das Angebot des Legaten zurückgewiesen: se semper velle ecclesiae inimicos, sed non omnes papae inimicos, impugnare. ${ }^{85}$ )

Friedrichs II. Feind wollte Håkon nicht werden. Die beiden Herrscher waren seit langem befreundet, und nun brauchte Håkon die Hilfe des Kaisers. Eines der großen Probleme der norwegischen Wirtschaft dieser Zeit war die unzureichende eigene Getreideproduktion. Norwegen war auf Getreideimporte angewiesen, und unter den Importeuren kam in der Mitte des 13. Jahrhunderts den hansischen Kaufleuten aus Lübeck eine ständig steigende Bedeutung $z u .{ }^{86}$ ) Das Interesse an einer Teilnahme am curopäischen Geschehen wurde natürlich auch von diesen handfesten Notwendigkeiten getragen, aber es ist ja gerade dieses Miteinander von tatsächlichem Bedarf und ideellem Wert, das einer

44) Dies bezeugt Mathäus Parisiensis, CM 5. Ed. Henry Richards Luard. London 1880, 201: Post hos autem onmes, roluit dominus Papa loco fretherici Haconem regem Norwagice in culmen imperii subrogare: ande ut aptiorem et favorabiliorem ad hoc ipsum haberet, ipsum in regem fecit consecratum coronart ... Et hoc idem protestatus est idem rex milhi ipsi Mathlaee, qui at haec scripsi, sub magni juramenti attestatione ... Der Chronist war im Jahr nach der Krönung Hakkons in Bergen. wo er durch eine glückliche lü̈gung nur knapp einem Unglück entrann. Während er das Schill verlassen hatte, um eine Messe zu hören, zerstörte cin Unwetter mit vielen anderen auch sein Schiff im Hafen ebenso wie Teile der Burg des Königs an der Hafeneinlahrt. König Häkon selbst ordnete an, den (iast für seine Verluste zu entschädigen: Matthäus Parisiensis. CM 5, 35 f. Matthäus verbrachte 1248 cinige \%eit in Norwegen, als er im Auftrag Innozenz. IV. das Benediktinerkloster Holm reformierte, ebd. $42-45$.

8.5) l:b(1. 201.

מ6) Vgl. zu dem Problem des Getreidehandels und der damit zusammenhängenden hansisch-norwegischen Beyiehungen die Literatur in Anm. 4. İinen ersten Niederschlag in den Quellen fanden diese Handelsberichungen in der hier untersuchen Zeit in verschiedenen Briefen Könie llakons an die läbecker: Codex Diplomaticus Lubecensis. Lübeckisches Lrkundenbuch (künftig: I.LB). Bd. 1/1. Lüibeck 1843 , Nr. 153. 154 und 157 
Bindung Zusammenhalt verleiht. Zu der Zeit, als Kardinal Wilhelm sich bei Håkon befand, geriet die norwegische Getreideversorgung in Gefahr. Dies war eine Folge von seit 1241 aufgeflammten Thronfolgekämpfen in Dänemark, in denen die Lübecker Partei ergriffen hatten. Daraus entwickelte sich eine Folge von Raub- und Kaperzügen zwischen Lübeck und der dänischen Küste. ${ }^{87}$ ) Bei ihren Beutezügen gegen nordische Kaufleute machten die Lübecker zur Verbitterung der Norweger keinen Unterschied zwischen dänischen und norwegischen Schiffen, und auch die Dänen hiclten sich an den Waren der norwegischen Händler schadlos ${ }^{88}$ ) So reagierte König Håkon schließlich mit der Beschlagnahme lübeckischer Schiffe im Hafen von Bergen. ${ }^{89}$ ) Die betroffenen Kaufleute suchten Hilfe beim Kardinal Wilhelm, der sich mit Erfolg für sic cinsetzte. ${ }^{90}$ )

Das Problem war dadurch nicht gelöst, norwegische Kaufleute wurden weiterhin aufgebracht und ihrer Güter beraubt. ${ }^{91}$ ) Schließlich wandte sich Hăkon hilfesuchend an Friedrich II. ${ }^{92}$ ) Nach Auskunft der Saga von Håkon soll Friedrich sich nachhaltig für den norwegischen Freund eingesetzt haben. ${ }^{93}$ ) Er habe dic Lübecker zum Frieden mit Hăkon angewiesen und mehr noch, er habe Hăkon in Aussicht gestellt, ihm die Stadtherrschaft abzutreten. wenn der Norweger die entsprechenden Urkunden bei ihm abholen lie(3e. $\left.{ }^{94}\right)$ Dic daraufhin nach Italien gereiste norwegische Gesandtschaft habe dann in Venedig vom Tod des Kaisers erlahren, wodurch das (Geschäft hinfällig wurde. ${ }^{95}$ )

Ein solches Angebot war wohl ein Mißßerständnis des ansonsten sehr gut informierten Chronisten. Friedrich II. selbst halte den Lübekkem im Reichstreiheitsprivileg von 1226 ausdrücklich zugesichert, dak er die Stadt niemals vom Reiche trennen wolle. ${ }^{96}$ ) Der Friedensschlub

\footnotetext{
87) Antjekalmin Grassmamn (Hrsg.), L übeckische Geschichte. Lübeck 1988. 123 f.

ss) Hakonarsaga (wie Anm. 32), Kap. 256.

s') Libd.

(")) libd.

91) Vgl. dazu die Korrespondenz. Hâkons mit Lübeck: LL'B (wic Anm. 86). Bd. 1/ 1. Nr. 153,154 u. 157.

"2) Ilakonarsaga ( wie Anm. 32). Kap. 275.

13.3) Fibd.

") Ebd. vgl. daru Brace Lduard (ie/singer: A Thirteenth-Century NorwegianCastilian Alliance, in: MedHum NS. 10, 1981. 55-80.

45) Iibd.

96) LUB (wie Anm. 86). Bd. 1/1, Nr. 35: vgl. dazu etwa Jan-Olof Ahlors u.a. (Hrsg.), Lübeck 1226. Reichsfreiloeit und früle Stadt. I.jiheck 1976; vgl. auch
} 
zwischen Håkon und den Lübeckern, der den Handel in Zukunft sichern sollte, kam dagegen noch vor Friedrichs Tod zustande ${ }^{97}$ )

Die politischen Ambitionen des norwegischen Königs richteten sich besonnen nach seinen Möglichkeiten. So wollte er durchaus teilnehmen am engeren europäischen Geschehen, sah seinen eigenen Platz aber nicht in der ersten Reihe. Diese Haltung schloß ein Bündnis und gute Beziehungen mit den exponierten Akteuren aber nicht aus, wie seine Kontakte mit der Kurie und mit Friedrich II. ja deutlich erwiesen. Dieses Bestreben stand wohl auch hinter einer zunächst überraschenden Allianz mit dem kastilischen König Alfons X. „el Sabio“ (12521282). ${ }^{98}$ )

Im Sommer 1255 schickte der norwegische Thronfolger, der wie sein Vater Håkon hieß, eine Gesandtschaft nach Kastilien. ${ }^{99}$ ) Ihr Auftrag ist nicht überliefert, aber sie wurde gut aufgenommen, und im folgenden Jahr fand sich eine kastilische Gesandtschaft bei König Håkon ein. ${ }^{100}$ ) Man führte lange Gespräche in freundschaftlicher Atmosphäre. Dabei wurde offenbar bereits über ein Heiratsprojekt verhandelt, das Håkons Tochter Christina mit einem Bruder von Alfons verbinden sollte. ${ }^{101}$ ) 1257 schließlich wurde es ernst. Die junge norwegische Prinzessin wurde in großzügiger Weise ausgestattet und mit groß3er Begleitung nach Kastilien geschickt. ${ }^{102}$ ) Stol $z$ vermerkı der Chronist, daß niemals

Georg Wilhelm von Brandr, Vogtei und Rektorat in Lübeck während des 13. Jahrhunderts, in: BlldLLG 107, 1971, 161-201.

97) LUB (wic Anm. 86), Bd. 1/1, Nr. 157 (6. Okt. 1250).

"98) Zu Alfons X. vgl. die klassische Biographic von Antonio Ballesteros-Beretta, Alfonso X el Sabio. Barcelona/Madrid/Buenos Aires u. a. 1963; außerdem: Joseph F. O'Callaghan, The Learned King. The Reign of Alfonso X of Castile. Philadelphia 1993; zur "Außenpolitik" von Alfons: Carlos de Ayala-Martinez. Directrizes fundamentales de la politica peninsular de Alfonso X. Madrid 1986. Eine entsprechende Nachfrage bei norwegischen Kollegen ergab, dal diese norwegischkastilische Allianz noch keine einschlägige neuere Bearbeitung gefunden hat, die einzige eingehende Studie bleibt daher Gelsinger; A Thirteenth-Century Alliance (wie Anm. 94).

1\%) Hakonarsaga (wic Anm. 32), Kap. 284.

I(ti) S Ebd. Kap. 287.

161) Ehd. Kap. 287 f.: vgl. auch die originelle Interpretation des Vorgangs bei Jenny M. Jochens, The Politics of Reproduction: Medieval Norwegian Kingship. in: AHR 92, 1987, 327--349, bes. 346-349, der in ihrer geschlechtsspezifischen Deutung dic Chronologie und die beteiligten Personen nicht unwesentlich durcheinandergeraten.

112) 7u dieser Episode: Hakonarsaga (wic Anm. 32), Kap. 290) u. 294-296. 
zuvor die Tochter eines norwegischen Königs eine solche Mitgift erhalten habe. Die glanzvolle Gesellschaft reiste über England und Frankreich - wo einige Begleiter die Gelegenheit zu einem Abstecher zu König Ludwig nutzten - nach Kastilien. ${ }^{103}$ ) Dort wurde die Prinzessin mit den heiratsfähigen Brüdern des Königs bekannt gemacht, und ihre Wahl fiel auf Philipp, der zwar zum Erzbischof von Sevilla ausersehen war, dessen Qualitäten aber wohl auf anderem Felde lagen. ${ }^{104}$ ) So willigte Christina in die Heirat ein, nachdem ihr zukünftiger Gemahl den Bau einer Kirche zu Ehren des hl. Olaf zugesagt hatte. Am Sonntag nach Ostern wurde die Hochzeit gefeiert. ${ }^{105}$ )

Das norwegische Königshaus knüpfte so nicht nur eine Verbindung zu dem bedeutenden kastilischen König, sondern gleichzeitig auch zum Inhaber des römischen Königstitels und möglichen Kandidaten für den Kaiserthron. Denn Alfons war, wenn auch in einer geteilten Wahl, am 1. April 1257 zum deutschen König gewählt worden. ${ }^{106}$ )

Entsprechende Ambitionen waren schon zwei Jahre zuvor angeklungen, als Alfons unter Berufung auf seine staufische Mutter nach dem Tode Konrads IV. 1254/55 Erbansprüche auf das Herzogtum Schwaben geltend machte. Anfang Februar forderte Papst Alcxander IV. offenbar

11.3) Ebd.

104) Ebd. Kap. 294. Philipp war ein begeisterter Jäger und kämpfte mit Vorliebe gegen Bären.

1115) Ebd.

116) MGH, Constitutiones 2 (wie Anm. 56), Nr. 397; erzählende Quellen: Annales Hamburgenses A. Hrsg. v. Johann Martin Lappenberg. (MGH Script., 16.) Hannover 1859, 384; Annales S. Rudherti Salisburgenses. Hrsg. v. Wilhelm Wattenbach. (MGH Script. 9.) Hannover 1851, 794: Gestorum Treverorum Contin. V. Hrsg. v. Georg Waitz. (MGH Script. 24.) Hannover 1879. 412 f. Zu Alfons" deutschem Königtum vgl. neben der bereits zitierten Literalur: Arnold Busson. Die Doppelwahl des Jahres 1257 und das römische Königtum Alfons X. von Castilien. Münster 1866. 7ur Wahl seines Kontrahenten auf den deutschen Thron. Richard von Cornwall. vgl, neben der Wahlanzeige, MGH Constitutiones 2 (wie Anm. 56), Nr. 385 , die Zusammenstellung der Quellen bei Joham Friedrich Böhmer/Julins Ficker (Hrsg.). Regesta Imperii 5/1. Innsbruck 1881/82, Nr. 5289a. Eine verläßliche und knappe Darstellung der Vorgänge noch immer bei: Herbert (Grundmann. Wahlkönigtum, Territorialpolitik und Ostbewegung. in: ders. (Hrsg.). Gebhardt. Handbuch der Deutschen Geschichte. Bd. 1. 9. Aufl. Stultgart 1970, 475. Zu Richard vgl. Noël Denholm-Young, Richard of Cornwall. Oxford 1947; zu Richards Wahl zuletzt: Hans-Lberhard Hilpert, Richard of Cornwall's Candidature for the German Throne. in: JMedH 6. 1980, 185-198: Manfred Groten, Konrad von Hochstaden und die Wahl Richards von Cornwall, in: Hanna Vollrath/Stefan Weinfurter (Hrsg.). Köln. Fschr. für Odilo Engels. Köln/Weimar/Wien 1993, 483-510. 
auf Ersuchen von Alfons den schwäbischen Adel auf, den Kastilier in seinen rechtmäßigen Ansprüchen zu unterstützen. ${ }^{107}$ ) Für diesen Zeitpunkt kann wohl ein gewisser Bekanntheitsgrad von Alfons' Absichten angenommen werden. $\mathrm{Ob}$ sie sich damals bereits für die Zeitgenossen erkennbar auf den deutschen Königsthron richteten und ob die norwegische Initiative vom Sommer 1255 damit zusammenhängt, ist nicht nachweisbar. ${ }^{108}$ ) Die Möglichkeit kann aber kaum ausgeschlossen werden, zumal gerade im Zeitraum Februar bis Mai 1255, als Alfons' Anliegen an der Kurie verhandelt wurde, ein intensiver Kontakt zwischen der Kurie und norwegischen Adressaten und Bittstellern feststellbar ist, der von seiten der Kurie nicht zuletzt darauf zielte, den Kreuzesschwur Håkons in eine Verpflichtung zur Teilnahme am Sizilienunternehmen von Heinrich III. von England umzuwandeln. ${ }^{109}$ )

So hatten dic Norweger einen durchaus respektablen Partner gewonnen. Der praktische Nutzen dieser Allianz für die Norweger ist dabei allerdings nicht ohne weiteres ersichtlich. Denn daß die Kastilier Håkon in konkreten Auseinandersetzungen behilflich sein würden, wie es das Bündnisversprechen vorsah -- mit der Ausnahme von Beistand gegen die Könige von Frankreich. Aragon und England -. war kaum denkbar. $\left.{ }^{10}\right)$ Auch ein anderer unmittelbarer Zweck, wic dic Sicherung der norwegischen Getreideversorgung, in der Gelsinger in jüngerer Zeit das Motiv des Bündnisses sah, ist so recht überzeugend nicht zu erkennen. ${ }^{11 !}$ )

197) Potthast, RPR (wic Anm. 15). Nr. 15670.

lik) Einen Zusammenhang nimm Gelsinger; A Thirten-Century Alliance (wie Anm. 94), 57 f.. an.

Ing) RN (wic Anm. 15), Bd. 1, Nr. $580=$ Pothlast, RPR (wie Anm. 15), Nr. 1.5706 (27.2); RN. Bd. I. Nr. 581 = Potthast, RPR. Nr. 1.5732 (I0.3); RN. Bd. I, Nr. $582=$ Potthast, RPR, Nr. 15735 (11.3): RN, Bd. I. Nr. $583 \mathrm{l}$. = Potthast, RPR. Nr. 15736 (12.3): RN, Bd. 1. Nr. $58.5=$ Potthast, RPR. Nr. 15764 (25.3): RN, Bd. I, Nr. $586=$ Potthast, RPR. Nr. 15775 (5.4): RN. Bd. 1, Nr. $588=$ Pothast. RPR. Nr. 15847 (11.5): RN. Bd. 1, Nr. 589 = Pothlast, RPR. Nr. 15853 (12.5); zum Sizilienproblem zuletzt: Gohard Backen, Ius Imperii ad Regnum. (Forsch. $z$. Kaiser- u. Papstgesch. (1. Mittelalters. 11.) Köln/Weimar/Wien 1993, 387-430) z. Heinrichs III. Sizilienpolitik: Frederick Matwice Powicke, King Henry III and the Lord Edward. Vol. 1. Oxford 1947. 343-409: zur Politik Alexanders IV.: Tenckhoff, Papsi Alexander IV. (wie Anm. 23). 24-75.

110) Hakonarsaga (wie Anm. 32). Kap. 296

111) Gelsinger; $\wedge$ Thirleenth-Century Alliance (wie $\Lambda$ nm. 94), trägt einen interessanten Deutungsversuch vor. It sieht das Ziel der fruhyeitig eingeleiteten norwegisch-kastilischen Verbindung in einer Neuaufnahme der vermeintlichen Abtre- 
Das Bündnis ist wohl gemeinsam mit den anderen vorgesteliten Initiativen als Bestreben $z u$ werten, den Kontakt mit dem engeren europäischen Geschehen aufrechtzuerhalten. Diese Kontakte waren, wie wir gesehen haben, durchaus nicht nur auf norwegische Initiativen zurückzuführen - wie etwa im Fall des hansischen Bergenhandels -, oder sie waren abhängig von günstigen Konstellationen, die einem lange anhängigen Wunsch nun eine Gelegenheit verschaflten, wie im Falle der Krönung Håkons. Aber diese Gelegenheiten waren eben auch eingebettet in eine bewußte Strategie der Orientierung an der mitteleuropäischen Kultur, zu der Hăkon wichtige Impulse gab. Diese Impulse wurden zumindest von einer interessierten Schicht seiner Landsleute aufgenommen.

Der etwa in cien Jahren um Håkons Krönung entstandene „Königsspiegel" eines unbekannten norwegischen Autors aus dem Umfeld des königlichen Hofes enthält deutliche Retlexe dieses Bestrebens. ${ }^{112}$ ) Der erste Teil des Werkes, das als Dialog zwischen erfahrenem Vater und wil3begierigem Sohn angelegt ist, handelt von den Kenntnissen, die ein Kaufmann und Secfahrer für seine Aufgabe braucht. Darin wird dem ambitionierten Kaufmann eine deutliche Empfehlung ausgesprochen: „Wenn Du vollkommen in deinen Kenntnissen werden willst, da lerne

tungspläne Friedrichs 1I. für Lübeck, die von Friedrichs Nachfolgern nicht weiterverfolgt worden waren. Hakon häte gehofft, durch eine früh\%eitige, enge Bindung an Kastilien die Abtretung Iübecks doch noch zol erreichen und dadurch den gefährdeten Getreideimport fïr sein Land sicher/ustellen. Ich diskutiere diese These in meiner Habilitationsschrift eingehender und möchte die Diskussion an dieser Stelle nicht weiterführen. Diese interessante, aher stark ,intentionale" Interprelation sieht die unwägbaren Bündnisrisiken des 13. Jahrhunderts wohl aus ciner allzu modernen Perspektive. Zudem hatte Hảkon sein Ziel einer Sicherung des Getreideimports ja durch den Handelswertrag mit Iübeck ron 1250 weitgehend erreicht.

112) Ludvig Holm-olson (tid.). Konungsskuggsjí. Oslo 1945. N1) 1982: ich zitiere nach der Übersetzung von Rudolf Meissner, Der Königspiegel. Konungsskuggsjá. Halle/S. 1944: \%um Königsspiegel vgl.: Wilhelm Berges. Die Fürstenspiegel des hohen und späten Mittelalters. (Schriften der MGH, 2.) Jeipzig 1938, 159-185 u. 314-317: Sierre Bagge. The Political Thought of the King s Mirror. Odense 1987. Wiahrend Borges, Fürstenspiegel. 159 u. 314. den Königsspiegel noch um 1260 dittiert, geht nun Bagge', $153 \mathrm{f}$. von einer etwas früheren Datierung zwischen 1247 und den späteren 5()er Jahren aus. Die geringe Differene ist für unsere Frage nicht erheblich. da es hier nicht 1 m das Verhälmis zu einem konkreten Vorfall, sondern den Ausdruck ciner ..kulturpolitischen" Haltung geht. 
du alle Sprachen und vor allem Latein und Französisch, denn diese Sprachen sind am weitesten verbreitet." 113 )

Mit diesen beiden Sprachen durfte der norwegische Kaufmann tatsächlich hoffen, in seinem nordeuropäischen Interessensbereich zurechtzukommen. Mit den meisten seiner Partner in den Nordseeländern konnte er sich mit ihnen verständigen, und falls es dennoch Probleme gab, so behalf man sich mit Dolmetschern. ${ }^{144}$ ) Daß erfolgreiche politische und kulturelle Kommunikation an Verständnisgrenzen stoßen konnte, wurde den Norwegern bei ihren europäischen Kontakten immer wieder klar. Diese Schwierigkeiten schränkten auch den ,internationalen" Aktionsradius der Norweger ein. ${ }^{115}$ ) Håkon, der wohl sah, daß die Sprachprobleme auch die Möglichkeiten kultureller Erfahrungen einschränkte, beließ es nicht dabei. Denn die Vermittlung europäischer kultureller Werte war ihm wichtig, und sein Bemühen richtete sich ganz im Geiste der Zeit auf die Werte, die besonders in der französischen Sprache ihren Ausdruck fanden: „Es sind drei Begriffe - doch fast sind alle zusammen nur eins - die man sorgfältig in acht zu nehmen hat: Mannesklugheit, gute Sitte, höfische Art" - so belehrte der Königsspiegel über die Erfordernisse im Umfeld des Königs. ${ }^{116}$ )

Dieser höfischen Kultur galı ein besonderes Bestreben König Håkons. Und da ihre Werte und Geschichten seinen Landsleuten in ihrer originalsprachlichen Fassung häufig unverständlich blieben, so regte er eine ganze Reihe von Übersetzungen an. Konrad Maurer sprach für den Zeitraum um die Mitte des 13.Jahrhunderts von einem ,.massenhaften Einströmen der eigentlichen Ritterromantik in Norwegen". ${ }^{117}$ ) Interes-

113) Meissner, Der Königspiegel (wie Anm. 112), 37.

$\left.{ }^{114}\right) \mathrm{Vgl}$. dazu: Bemhard Bischoff. The Study of Foreign Languages in the Middle Ages, in: Spec 36. 1961, 209-224; Llse Ebel, Der Fernhandel von der Wikingerzeit bis in das 12. Jahrhundert in Nordeuropa nach altnordischen Quellen. in: Klaus Düwel u. a. (Hrsg.), Untersuchungen zu Handel und Verkehr der vor- und frühgeschichtlichen Zeit in Mittel- und Nordeuropa. ( $\Lambda$ bh. d. Akad. d. Wiss. in Göttingen, philol-hist. Klasse, 3. Folge, Nr. 156.) Göttingen 1987, 266-312, bes. 2861 . u. 312. 115) Vol. oben Anm. 21.

116) Meissner: Königspiegel (wie $\Lambda$ nm. 112). 148.

117) Konrad Maturer, Islands und Norwegens Verkehr mit dem Süden vom IX. bis XIII. Jahrhundert, in: \%dtPhil 2. 1870, 440-468, 464: vgl. auch Fredrik Paasche, Über Rom und das Nachleben der Antike im norwegischen und isländischen Schriftum des Hochmittelalters, in: Symbolac Osloenses 13, 1934, 114 f:; 70 Hảkous Engagement für Übersetzungen ins Altnordische vgl, vor allem Henry Goddard Leach. Angevin Britain and Scandinavia. (Harvard Stud. in Comparative Literature, 6.) Cambridge. Mass. 1921. ND New York 1975. 
sant und auch aufschlußreich ist es, daß sich insbesondere isländische Gelehrte bei diesen Übersetzungen ins Altnordische hervortaten. Ein Phänomen, das man geradezu als exemplarische Umsetzung des Modells von „challenge“ und ,response“ verstehen könnte, wenn man sich die Ausgangssituation auf dieser kargen Insel an der Peripherie Europas vor Augen hält. ${ }^{118}$ ) Aber auch die Norweger nahmen sich der Aufgabe an, und die Universitätsbibliothek Uppsala verwahrt das Exemplar einer um 1250 entstandenen Übersetzung eines „Buches der Laisse" - einer altnordischen Fassung von erbaulichen epischen Geschichten eines bretonischen Poeten, die nach der Vorbemerkung des Übersetzers auf Geheiß König Håkons angefertigt wurde. ${ }^{19}$ ) Der Übersetzer adaptierte durchaus eigenständig und fügte etwa der Geschichte über einen Mann, der als Werwolf ein doppeltes Spiel seiner Gattin erleiden muß, bevor diese dic gerechte Strafe trifft, eine Anmerkung über eigene Erfahrungen mit cinem Werwolf in seiner Jugend hinzu. ${ }^{120}$ ) Die übertragene Dichtung hatte allgemein eine gewisse Anpassung an eine etwas robustere Situation hinzunehmen, das gesamte Projekt aber war eine enorme Leistung. ${ }^{121}$ )

Eine schöne Geschichte über die Überlieferung der Blómstrvalla saga, die der Erzbischof von Trondheim bei der Hochzeitsfeier von Prinzessin Christina in Kastilien auf deutsch vorgetragen hörte und die er dann seinem König Håkon gleich nach der Rückkehr erıählte - wic es die Einleitung der Saga berichtet -, ist aber wohl eine sehr viel spätere Konstruktion. dic auf der Rezeption der Hakonarsaga beruht und nicht auf erlebter Überlieferung. ${ }^{122}$ )

1is) Vgl. dazu neben der bislang genannten Literatur: Temney Frank, Classical Scholarship in Medieval Iceland. in: $\mathrm{AJPh}$ 30, 1909. 139-152; Kirsten Hastrup, Culture and History in Early Medieval Lceland. Oxford 1985; Jesse L. Brock. Medieval Iceland. Society. Sagas and Power. Berkeley 1988; vgl auch: Komrad Manror Island. Von seiner ersten Enteckung bis zum Untergang des Freistates (ca. 80)-1264). München 1874. ND 1969, sowie Hermann Kamp, Kontlikte und ihre Beilegung. Ein Blick auf einige Neucrscheinungen zur isländischen und norwegischen Geschichte, in: H7. 259. 1994, 391-409.

119) Uppsala Universität. De la Gardic 4-7: Edition: Robent Cook/Mathias Ticitale (Eds.). Strengleikar. An Old Norse Translation of Twenty-one Old French I ais. (Norsk historisk kjeldeschrift-institutt Nörröne tekster. 3.) Oslo 1979. der Verweis auf Häkon chd. 4f: vgl. dazu Leach. Angevin Britain (wie Anm. 117). 199-226.

120) Cookflieitone (Eds.). Strengleikar (wie Anm. 119). $98 \mathrm{f}$.

121) Vgl. elwa Leench, Angerin Britain (wie Anm. 117). 11.5 u. 150) f.

12?) Theodor; Möbius (Hrsg.), Blómstrvalla sagal. Leciprig 1855, 2; vgl. auch: Fromk Hugus, Blómstrvalla saga: A Critical IEdition of an Original Icelandic Romance. 
Wenn wir also auf diese Synthese der bisher dargestellten norwegischen Kontakte in Europa nicht verläßlich zurückgreifen können, so können wir doch manche anderen Rückwirkungen dieser Kontakte feststellen. Der direkte kulturelle Einfluß, den die Deutschen hinterlieBen, ist zunächst einmal überschaubar. Sie prägten einen Teil des Erscheinungsbildes am königlichen Hof, wo es nach Auskunft des $\mathrm{Kö-}$ nigsspiegels in den frühen Jahren von Håkons Regicrung üblich war, den „Backenbart nach deutscher Art“ zu tragen. ${ }^{123}$ )

Erheblich stärker war der englische Einfluß, und das verwundert auch kaum, wenn man die jahrhundertelange enge Beziehung beider Länder bedenkt. Die Christianisierung und der Aufbau der norwegischen Kirche war von den Anfängen bis in das fortgeschrittene 13. Jahrhundert wesentlich von der englischen Kirche unterstïtzt worden, und persönliche Bezichungen bestanden weiterhin. ${ }^{124}$ ) Im Rahmen dieser Tradition war auch der Benediktiner Matthäus Parisiensis, der Chronist von St. Albans, nach Norwegen gelangt, dem wir eine Reihe wertvoller Informationen verdanken. ${ }^{25}$ )

Die unterschiedlichen Grade des kulturellen Einflusses wurden auch bei Hof sehr deutlich. Mochte das königliche Gefolge cinen deutschen Bart tragen, der König trug eine englische Krone. Heinrich III. Ließ sie ihm 1251 nach dem Vorbild der eigenen anfertigen. ${ }^{126}$ )

Auch das Haus des Königs entstand nach englischem Vorbild. Wahrscheinlich veranlaßi durch das Feuer, das nach dem Zeugnis des Matthäus auch einen großen Teil der königlichen Burganlage an der Hafeneinfahrt von Bergen - Bergenhus genannt - zerstörte. vielleicht auch

Diss. Chicago 1972: vgl zu der Cherlieferungsgeschichte: leach. Angevin Britain (wie Anm. 117). 165: Springes: Medieval Pilgrim Routes (wic Anm. 6). 94: zur Kritik aber: Fronk Ihuguss. Blómstrvalla Saga, in: Phillip Pulsiano/Kirsten Woif (Eds.). Medieval Scandinavia. An Encyclopedial. New York/London 1993. 50 f.

13) Meissn'; Der Königspicgel (wie Anm. 112). 114.

124) Vgl. etwat Leach, Angevin Britain (wie Anm. 117). 87. 96f.. 113, zu einem Uberblick ïber die englisch-norwegischen Beriehungen ebd. 36 72: Knut Helle, Trade and Shipping between Norway and Ingland in the Reign of I Jíkon Hakonsson (1217 1263). in: Sjöfartshist. arbok (Norwegian Yearbook of Maritinc History. Bergen) 1967. 7-34: ders. Norwegian Foreign Policy and the Maid of Nomay. in: Scothrev 69. 1990). 142-150.

(2.) Neben der bereits zitierten Literatur zu Matthäus vgl, uber seinen VorwegenAufenthalt auch: Leadh, Angevin Britain (wie Amm. 117), 1031:: Darid Knowles. The Religious Orders in Iingland. Vol. 1. Cambridge 1956. 294 $\mathrm{f}$.

1\%) Leach. Angevin Britain (wie Anm. 117). 110. 
aus dem Wunsch heraus, seiner aufgewerteten königlichen Stellung angemessenen Ausdruck zu verleihen, ließ Håkon nach 1248 eine imposante Königshalle bauen. ${ }^{127}$ ) Der königliche Profanbau orientierte sich an der englischen Architektur. ${ }^{128}$ ) Dic kunstgeschichtliche Forschung hat neben den architektonischen auch Einflüsse englischer Vorbilder auf die norwegische Skulpturenkunst in der Zeit Håkons aufgezeigt. ${ }^{129}$ ) So ist in der öffentlichen Darstellung des norwegischen Königs und auch der norwegischen Kirche cine Orientierung an europäischen Entwicklungen erkennbar, die insbesondere durch englische Kontakte vermittelt wurden.

Ein abschließendes Beispiel illustriert noch einmal den Entwicklungsstand, den Norwegen dabei erreicht hatte, und die Orientierung, die es dabei suchte, schlïgt den Bogen zurück zu der Ausgangsfrage. Die fortgeschrittene Rechtswissenschaft und die mit ihr einhergehende Zunahme der Bedeutung juristischer Argumentation im Austrag zentraler Konflikte im kirchlichen und politischen Lechen ist eines der markanten Kennzeichen der intellektuellen und administrativen Situation im Mitteleuropa des fortgeschrittenen 13. Jahrhunderts. ${ }^{30}$ ) Damit einher ging die Bedeutung schriftlicher Rechtsdokumente, von Privilegien und Rechtsverbriefungen in diesen Konflikten. Sowohl Innozenz. IV. als auch der Vertreter des Kaisers, Thadeus von Suessa, hatten auf dem Konzil von Lyon 1245 in ihrem Ringen um die Rechmmïßigkeit des

127) Matthäus Parisiensis, CM 5 (wie Anm. 84). 36: Castrum ('nim, quod erat maximis et durissimis construtum molaribus, pro majori parte redactum est in faritlas. In derselben Passage. cbd. 35. nennt Matthäus auch das fast gleichzeitige Unglück in Köln, das schlieblich zum Neubau des Dones führte. Beide Feuer wurden vielleicht nicht nur als Schicksalsschlag empfunden. Zu Hakons Batutätigkeit vgl. auch die llatkonarsagal (wie Anm. 32), Kap. 333.

Is, Vgl. zur Hakonshalle: Williom-Douglas Simpsom. The Castle of Bergen and the Bishop 's Palace at Kirkwall. (Aberdeen Lniversity Stud.. 142.) Lelinburgh/London 1961: vgl. allgennein /u ciner C̈bersicht über den Linflul3 der englischen Architektur in Vorwegen: (Oto vom Simson. Das lwohe Mittclalter. (Propyläen Kunstgeschichte, 6.) Berlin 1985. 1981. 11. 306 f. Die Hakonshalle wird 1261 erstmals erwähnt: Hakonarsaga (wie Anm. 32). Kap. 308.

12y) Vgl. Arom Anderson, English Influence in Vorwegian and Swedish Figure Sculpture in Wood 1220 1270. Stockholun 1950; Martin Blindherim, Main Trends of East-Norwegian Iigure Sculpture in the Second Half of the Thirteenth-Century. (Oslo 1952 .

1.i0) Vgl. zu cinem Überblick: /I'/mun Coimg (Hrsg.). Handbuch der Quellen und literatur der neteren europaiischen Privatrechtsgeschichte. Bd. I. München 197.3. 
päpstlichen Absetzungsurteils mit solchen Texten argumentiert, die sie dem Konzil in authentischen Fassungen vorlegten. ${ }^{131}$ )

Eine solche Entwicklung brachte Probleme mit sich. Die wichtigsten Dokumente mußten sicher verwahrt werden, aber sie mußten auch verfügbar sein. Die Unsicherheiten des Weges, noch verschärft durch eine zugespitzte Konfliktsituation, stellten jeweils erhebliche Gefahren dar. Auch Innozenz trug dieser Unsicherheit Rechnung und ließ während des Konzils alle Dokumente, die ihm für die Rechtsstellung des apostolischen Stuhles wichtig erschienen, abschreiben. Es entstanden auf diese Weise 17 Pergamentrotuli, von denen Innozenz sicherheitshalber gleich mehrere Exemplare anfertigen ließ. Eine Reihe dieser Sicherheitsabschriften hinterlegte er im Kloster Cluny. ${ }^{132}$ ) Das Sicherheitsproblem veranlaßte Innozenz auch, 1254 die Ernennung Bertholds von Hohenburg zum Seneschall von Sizilien dem Adressaten nur als Transsumpt zuzustellen und das Original an der Kurie zu verwahren - der Gefahren des Weges in dem hart umkämpften Lande wegen. ${ }^{133}$ )

Überlegungen der Sicherheit und der praktischen Verfügbarkeit waren es wohl auch, die Heinrich III. von England 1243 dazu veranlaliten, die Privilegien der päpstlichen Vorgänger von Innozenz IV. für die englische Krone kopieren zu lassen, damit sie seine Gesandten an die Kuric mitnehmen konnten. ${ }^{134}$ ) Es ist aus der Weisung nicht hinreichend ersichtlich, ob auf diese Weise dem Gesandten lediglich die Texte für Verhandlungen bereitgestellt wurden oder ob sie etwa bei der Kurie deponiert werden sollten. Ein solches Verständnis von der Kurie gleichsam als curopäischem Archiv aber findel sich in Norwegen im hicr behandelten Zeitraum. Der Ersbischof von Trondheim und sein Kapitel

1.31) Math äus Parisiensis, CM 4 (wie Anm. 73), 435: Super quibus ut magis haed audientes certificaret, signormm imperialiam de aluo appensione communitas |Innocentius| ostendit epistolas, multas et multiplices, quibus evidenter arguit et redarguit ipsum super perjuro. Quibus etiam verbis alacriter se opposuit Thadaens, se tume erigens impenterritus in publico, ostendens o contra literas Papales bullatas, quac videbantur jam dictis obviare ... Zur Absetzung des Kaisers vgl. Friedrich Kempf, Dic Absetzung Friedrichs II. im Lichte der Kanonistik. in: Josef Ileckenstein (Hrsg.). Probleme um Iriedrich Il. (Vul: 16.) Sigmaringen 1974, $345-360$.

1:2) Bresslau, Handbuch der L'rkundenlehre (wic Anm. 68). Bd. I. 155 f.

1:i.) Thomas Rimer (Fd.). Foedera. Conventiones. Literae el cujuscunque generis Acta publica. Vol. 1/1. 3. Aufl. Den Haag 1745. 189.

1.3) Close Rolls of the Reign ol Henry III. Vol. 5 (1242-47). London 1915. NI) Nendeln 1970. 146. 
hofften in diesen Jahren, ihre Privilegien durch entsprechende Hinterlegung in Rom sichern zu können. Die Sorge um den Bestand ihrer wichtigen Dokumente veranlaßte sie zu diesem Schritt: que propter nimiam vetustatem ac etiam minus diligentem custodiam adeo sunt consumpta, quod de destructione timetur non modicum eorundem. ${ }^{135}$ )

Innozenz erklärte sich zu einer Verwahrung bereit und instruierte die Norweger noch aus Lyon, wörtliche Kopien der lateinischen Dokumente anzufertigen und zu besiegeln und die norwegischen Dokumente in eine lateinische Fassung zu übertragen. Alle Personen, deren Rechte tangiert waren und die noch erreicht werden konnten, sollten zu dem Vorgang geladen werden. ${ }^{136}$ ) Das Vertrauen der norwegischen Kirchenleitung auf die Standards der römischen Kurie kommt in diesem Schritt besonders deutlich zum Ausdruck, einschließlich der Tatsache, daß der erhoffte Sicherheitsgewinn dic Beherrschung der lateinischen Sprache voraussetzte.

Damit ist das Spektrum der kulturellen, politischen und - bei allen Vorbehalten - administrativen Initiativen skizziert, mit denen die Norweger in der Zeit ihres Königs Hăkon cine Einbindung in das mitteleuropäische Geschehen suchten. Es ist die Geschichte der ernsthaften und breit gefächerten Integrationsbemühungen der Norweger in die europäische Entwicklung.

Ernsthaft und erfolgreich. Erfolgreich insofern, als dieses Land, das auch für Innozenz IV. noch am Rande der bewohnbaren Welt lag, nun in die Erwägungen des europäischen Kräftespiels mit cinbezogen wurde. Halten sich die Norweger in besonderer Weise um kuriale Anerkennung und um die Rezeption der höfischen Kultur, deren Heimat Frankreich war, bemüht, so erwiesen ihnen diese beiden europäischen Machtzentren, dic Kurie und der französische Königshof, nun ihren Respekt.

Zu den großen politischen Themen und Problemen der vierziger und fünfziger Jahre des 13. Jahrhunderts gehörten sicher der Kampf der Kurie mit Friedrich II. und der Kreuzzug Ludwigs IX., der sich im Konflikt des Kaisers mit dem Papst weitgehend neutral verhalten hatte. ${ }^{137}$ )

135) IDN (wie Anm. 1), Bd. I, Nr. 45

1.36) Ebd.

1.37) Zam Kampf zwischen Kaiser und Kurie vgl. die bereits genannte Literatur: zu I.udwig IX.: Gerard Sivery: Saint I.ouis et son Siecle. Paris 1983: Jean Richard, Saint Louis. O. O. 1983; Jarques le Goff. Saint Louis. (). O. 1996; zu Ludwigs Kreurag den Bericht eines Teilnehners. Jean de Jomville, Histoire de Saint I ouis. 
Der Kreuzzug wurde zu einem Lebensthema Ludwigs, und er bereitete ihn nach seiner Kreuzesnahme 1244 bis zum Aufbruch 1248 mit großer Umsicht vor. ${ }^{138}$ ) Es ist daher ein Beleg seiner Wertschätzung, daß der französische König dem Norweger Håkon nach dessen Krönung das Kommando über seine Kreuzzugsflotte antrug. Das Einladungsschreiben wurde Håkon von Matthäus Parisiensis persönlich überbracht, der auch die ablehnende Antwort des Norwegers überliefert. ${ }^{139}$ )

Auch auf die zweite Einladung in hohe Würden ging Håkon nicht ein: Die Kaiserkrone lehnte er ab, die ihm anläßlich seiner Krönung von Kardinal Wilhelm angetragen wurde. ${ }^{140}$ ) Das Angebot dieser Krone ist ein deutlicher Beleg für den Prestigegewinn, den das norwegische Königtum unter Håkon im europäischen Umfeld verzeichnen konnte. Es licße sich aus anderer Sicht dagegen argumenticren, daß der Ruf an Hăkon das Gegenteil belege, denn Innozenz IV. sei ja ein machtloser Schattenkaiser gerade erwünscht gewesen. ${ }^{141}$ )

Die Argumentation verkennt aber dic Situation, in der sich Innozenz. an den Norweger wandte. Mit Heinrich Raspe und Wilhelm von Holland hatte die Kuric eben enttäuschende Erfahrungen gemacht, und was nützte ihr ein ohnmächtiger Titelträger, wenn sic in Friedrich II. noch immer einen mächtigen Feind hatte? ${ }^{142}$ ) Einen Feind, der sich seiner Lage so sicher war, daß er nach dem Tode Heinrich Raspes schon zu einem Zug nach Lyon aufgebrochen war. ${ }^{143}$ ) Die Kurie brauchte einen schlagkräftigen Verbündeten.

Ed. Natalis de Wailly. 2. Aufl. Paris 1874; aukerdem: William Chester Jordan, Louis IX and the Challenge of the Crusade. Princeton 1979.

1.38) Vgl. Jorkim. Challenge (wie Anm, 137), 3-104.

13) Matthäus Parisiensis, CM 4 (wie Anm. 73), 651: ... committeretur namque oidem regi Illaconil. quia in mari potens. est et peritus, totius navigii sui dominium, regimen, et potestas; exercitus quoque Irancorum ejusdem nutui pro magna parte ex tunc inclinaretur; vgl. auch den Brief Ludwigs IX.. chd. 652.

1.16) Mathä̈rs Parisicnsis, CM 5 (wic Anm. 84). 2()1.

1.ti) Dieses Argument wurde mir wiederholt won Kollegen entgegengehalten. die den Zeitram einschlïgig bearbeitet haben und mit denen ich einen $\Lambda$ ustausch gesucht hathe. lch halte es trote ihrer Erlathrung für nicht zutreffend.

1.+2) Vgl. dizu Mathäus P'arisiensis. CM 5 (wie Anm. 84), 200f., wo diese Situaltion ganz deutlich wird.

1.15) \%ur Situation Friedrichs II. im Fruhsommer 1247: Böhmer/ficker, Regesta Imperii $5 / 1$ (wie Anm. 106). Nr. $3578 f$.. Nr. 3608 a u. Nr. 3626a: vgl. auch Kantorowic-, Kaiser Friedrich (wie Anm. 53), 582-589. Dic Entwicklung, die nach dem falle Parmas eine Verschicbung der Krätte cinleitete, setze später ein und konnte auf das norwegische Kaiserprojekt noch keinen Einfluß nehmen. 
Daß sie in dieser Krisensituation auf die Norweger hoffte, zeigte sich auch, als Innozenz IV. im November 1250 nach der Niederlage der französischen Kreuzfahrer und der Gefangennahme ihres Königs einen dringenden Aufruf zur Mobilisierung des norwegischen Kreuzzugskontingentes erließ. ${ }^{144}$ ) Einige Norweger erreichten auch tatsächlich das Heilige Land, wo sie in Akkon zu den Franzosen stießen. ${ }^{145}$ )

Natürlich ging es hier nicht um die Wunschbesetzung des Papstes für die in Rede stehenden Aufgaben, dazu war Norwegen schon ganz einfach zu weit entfernt von den Stätten des Geschehens. Natürlich war es auch die Entwicklung der Umstände, der Kräfte und der Möglichkeiten der Kurie, die diese Situation entstehen ließ, in der die Norweger für die engeren Lösungen der großen europäischen Probleme in Betracht kamen. Aber diese Entwicklungen sind ja der Stoff der Geschichte, zumal die Norweger diese Integration durch geziclte eigene Maßnahmen betricben hatten. Dies ist das eigentlich Interessante: das Bemühen ist noch cbenso erkennbar wie der Erfolg.

Was gewinnen wir auf diese Weise, wenn wir in anderer Akzentuierung als die bisherige Forschung dic Vielfalt der norwegischen Integrationsbemühungen betonen? Zunächst einmal wird das Bild diffuser, wenn nicht mehr in erster Linie die Kurie oder der norwegische Wunsch nach der Sicherung von Getreideimporten als Erklärung für die auffälligeren Ereignisse im Verlaufe dieses Vorgangs herangezogen werden. Auch der Wunsch Häkons nach weiteren Titeln ist keine ausreichende Erklärung, denn er lehnte die ihm angetragenen, chrenvollen Angebote ja ab. Wobei er in der Beurteilung seiner Möglichkeiten realistischer und damit als König auch erfolgreicher blieb als sein ambitionierter Bündnispartner Alfons X.. der sich über seine Wathl zum römischen König und Kaiser nicht nur freute, sondern sie auch annahm. Dieser überzogene Integrationsversuch trug auch zu Alfons' innenpolitischem Scheitern bei. ${ }^{160}$ )

Für Häkon bestand der greifbarste Erfolg seiner Bemühungen in der

14-) Lucas Wadding (Ed.), Annales Minorum III. Quaracchi 1931, 247 (S. 281) = Pothast, RPR (wie Anm. 15). Nr. 14121.

1.15) Joimille. Histoire (wie Anm. 137). Kap. 96: vgl. anch Jorklan, (hallenge (wie Amm. 137). 69. Jorden chd. 81 f.. beurteilt die Krewzfahrtpolitik I Hakons aus der Sicht der Frfordernisse des Heiligen I andes nicht sehr zustimmend.

1.th) I.iteratur \%u Altons wie Anm. 106: vgl, auBerdem zu diesem Problem: Ladwig Vones, Geschichte der iberischen Halbinsel im Mittelalter 711 -1480. Sigmaringen 1993. 147-152. 
Krönung durch den päpstlichen Legaten im Sommer 1247, die das Ansehen seines Königtums nicht nur in Europa, sondern auch in Norwegen festigte. Aber mit diesem Erfolg endeten die Integrationsbemühungen nicht, und das Spektrum dieser Bemühungen zeigt auch, daß sie nicht nur vom König ausgingen. So wird das Bild diffuser, aber auch vollständiger. Die Kontakte Norwegens mit Europa wurden offenbar getragen von einem gewissen gesellschaftlichen Interesse. Das schließt Auseinandersetzungen über das Thema nicht aus, im Gegenteil - ,gesellschaftliche" Themen fordern immer auch Gegner heraus. ${ }^{147}$ ) Auch war das Bemühen um die Teilnahme am europäischen Geschehen nicht Håkons Hauptsorge, diese galt vor allem der skandinavischen Position seines Landes. ${ }^{148}$ ) Aber das Integrationsbemühen, das dabei immer auch um die Vorteile der Distanz wußte, war doch ein bedeutender Aspekt einer Regierungstätigkeit, die vor einem europäischen Horizont politische Chancen mit kultureller Neugier zu verbinden und abzuwägen wußte und damit den Norwegern einen Höhepunkt ihrer mittelalterlichen Geschichte crmöglichte. Eine nüchterne Offenheit gegenüber dem curopäischen Geschehen war dic treibende Kraft der hier geschilderten Kontakte. Mit Blick auf die anfangs aufgeworfene Frage handelte es sich also nicht um die Geschichte einer vorbehaltlosen Integration, sondern um einen Prozel souveräner, enger Kontaktaufnahme, die durchaus von den Chancen der europäischen Krisensituation nach dem Konflikt Friedrichs II. mit der Kurie profitierte. Die Fülle der Initiativen, dic wir hicr in den Blick genommen haben, darf letztlich nicht nur aus einer Frage nach Motiven und Nutzen heraus interpretiert werden. Das Bemühen um eine Teilnahme an der europäischen Entwicklung ist wohl doch nur durch die Kraft kultureller Werte und Vorbilder vollständig zu erklären.

Gleich \%eitig verweist der untersuchte Vorgang sehr klar auf die Bedingungen und Grenzen solcher Integration im 13. Jahrhundert. Denn es entstanden keine tragenden Strukturen. Die Kommunikation war je-

1.47) Es hat in Norwegen, insbesondere an den Handel spläte durchaus auch erhebliche Probleme mit den Fremden gegeben. Das Problem dieser Konflikte ist insbesondere von der Hansegeschichte und ihrem norwegischen Widerpart beachtet worden: vgl. Anm. 4.

148) Vgl. dazu den knappen und kenntmisreichen Überblick von Ahasier von Brandi/Lrich Ioffmann, Die nordischen I änder von der Mitte des 11 . Jahrhunderts bis 1448, in: Theodor Schieder (Hrsg.), Handbuch der europiaischen Geschichte. Bd. 2. Stuttgart 1987, 884-917. 887-9(00). 
weils wieder neu auf die Initiative einzelner Personen angewiesen. Die Norweger mußten die seltenen Gäste wie Nikolaus von Albano und ein Jahrhundert später Wilhelm von Sabina persönlich für ihr Land und seine Menschen gewinnen, um künftig in Rom Ansprechpartner mit offenem Ohr für ihre Probleme zu finden. Auch sicherte ein guter Ruf an den Höfen europäischer Könige noch keinen europäischen Bekanntheitsgrad. So konnte Jean de Joinville, der Biograph des französischen Königs, der den Norweger für eine wichtige Position in seiner Kreuzzugsflotte gewinnen wollte, anläßlich der Ankunft des norwegischen Kontingents in Akkon über das Herkunftsland bemerken: qui est en la fin dou monde devers Occident. ${ }^{149}$ )

Kommunikationserfolge hingen stark von der persönlichen Initiative ab, und so veränderte sich das Verhältnis Norwegens zu Europa nach Haikons Tod. Zumal es auch Entwicklungen gab, die durch die Initiative einzelner nicht aufzuhalten waren, wie etwa den wachsenden Einfluß der hansischen Kaufleute in Norwegen, die ihre Macht 1284/85 in einer Handelsblockade erstmals massiv unter Bewcis stelten. Diese spätere Entwicklung wird zumindest von norwegischen Historikern nicht als gelungene Integration verstanden.

Damals aber war Håkon schon 20 Jahre tot. Während seiner Regicrungszeit hatte er sich im Interesse seines Königtums und seines Landes um enge europäische Kontakte bemüht, etliche Norweger hatten es ihm darin gleichgetan, und diese Bestrebungen hatten erheblichen Erfolg. Die enge Verbindung der Norweger zur Kuric, die cine der Ausgangsfragen dieser Untersuchung war, wirkte auch darin nach, daß Norwegen 1274 das einzige skandinavische Land war, das auf dem zweiten Konzil von Lyon durch eine königliche Gesandtschaft vertreten wurde. ${ }^{150}$ )

\section{Zusammenfassung}

Der Beitrag untersucht das Spektrum der norwegischen Kontakte mit dem Papsttum und den europäischen Kernliindern (v.a. England. Frankreich und Deutschland) in der Zeit Hăkons IV. (1217-1263). Die bislang bekannten politischen Initiativen (Hăkons Krönung durch einen

1.49) Joimille, Histoire (wie Anm. 137). Katp. 96.

151) Burkhard Roberg. Das zweite Konzil von Lyon [1274]. (Konziliengeschichte, Rh. A.) Paderborn/München/Wien//ärich 1990. 54-56. 
päpstlichen Legaten, das Angebot der Kaiserkrone, das norwegisch-kastilische Bündnis) werden dabei in einem engen Zusammenhang mit der gleichzeitigen Rezeption kultureller europäischer Standards in Norwegen interpretiert. Das norwegische Interesse an diesen Standards wird seit den 30er Jahren des 13. Jahrhunderts deutlich intensiver und läßt sich in der Zeit Håkons als ein Prozeß bewußter Hinwendung zum europäischen Zentrum interpretieren. Diese Orientierung führte im Gegenzug dazu, daß die Norweger zunehmend in die politischen Szenarien dieser europäischen Umbruchszeit einbezogen wurden. Sie nutzten diese neuen Möglichkeiten mit zurückhaltender Umsicht. Der Vorgang zeigt damit eine bedeutende Facette erfolgreichen königlichen Handelns in der norwegischen Geschichte des 13. Jahrhunderts und ist zugleich ein Modellfall für das Studium der Kontakte von kultureller Peripherie und europäischem Zentrum. 